\title{
LOS ARGUMENTOS DE EFICACIA EN EL DISCURSO PARLAMENTARIO *
}

\author{
A. Daniel Oliver-Lalana ** \\ Universidad de Bruselas (HUB)
}

RESUMEN. Este trabajo aborda la relación entre justificación racional y eficacia de las leyes desde el punto de vista de una teoría de la argumentación parlamentaria. Dentro de este marco me centraré en la cuestión de cómo son tratados y qué relevancia tienen en el discurso de los legisladores los problemas relativos a la eficacia social del Derecho. Intento primero clarificar cuál es el papel de la eficacia en la racionalidad legislativa, para discutir luego, a propósito de la dimensión simbólica de las normas, en qué medida la argumentación durante (y después de) la formación de la ley condiciona su capacidad regulativa. Sobre esta base planteo un modelo para analizar los argumentos de eficacia en la discusión parlamentaria de las leyes y, a modo de ejemplo, lo aplico a los debates sobre la modificación del código civil español en materia de matrimonio.

Palabras clave: argumentación legislativa, debate parlamentario, teoría de la legislación, argumentación jurídica, eficacia del Derecho, evaluación legislativa, democracia deliberativa.

ABSTRACT. This paper addresses the connection between rational justification and effectiveness of laws under the light of a theory of parliamentary argumentation. Within this framework, here the focus is on how problems concerning legal effectiveness are dealt with and what relevance they may have in legislators' discourse. The paper firstly considers the role of effectiveness in legislative rationality and discusses to what extent argumentation during and after the making of statutes may contribute to their steering or regulatory function (in this respect, the symbolic dimension of norms comes to the fore). Upon this basis, a model is outlined to analyze arguments on effectiveness within parliamentary deliberation about laws. In the last section, I will tentatively apply it to the legislative debates on the Spanish same-sex marriage act.

Keywords: legislative argumentation, parliamentary debate, legislation theory, legal argumentation, effectiveness of law, legislative evaluation, deliberative democracy.

\footnotetext{
* Fecha de recepción: 3 de diciembre de 2008. Fecha de aceptación: 18 de diciembre de 2008.

** Quisiera agradecer a los profesores J. Delgado, M. ATIENZA y M. CAlvo sus indicaciones bibliográficas y observaciones críticas sobre este trabajo; también estoy en deuda con los participantes en el Taller «Argumentación en el proceso de producción y aplicación del Derecho» (IISJ Oñati, 2008) y el Seminario «Argumentación jurídica y praxis del Derecho en Latinoamérica» (Universidad de Alicante, 2008), donde tuve la ocasión de discutir las ideas fundamentales que se exponen aquí.
} 


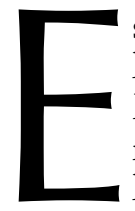

ste trabajo aborda la relación entre la justificación racional y la eficacia de las leyes desde el punto de vista de una teoría de la argumentación parlamentaria. Mi asunción de partida es que nuestros representantes -idealmente al menos- sopesan y discuten en el parlamento las razones por las cuales legislan. Sus deliberaciones deberían proporcionar entonces una justificación pública de las normas que aprueban, de modo que los ciudadanos pudiesen valorar la racionalidad y legitimidad de su actuación. Parece obvio que entre los problemas fundamentales que han de considerarse al elaborar una ley están los relativos a su eficacia social, pero ¿qué relevancia se les concede en el discurso de los legisladores? Para intentar responder esta cuestión, y tras introducir varias acepciones del concepto de eficacia [1], señalaré qué papel desempeñan dentro de la racionalidad legislativa [2], y en qué medida la argumentación durante y después de la formación de la ley puede constituir un presupuesto de su capacidad regulativa [3]. Plantearé a continuación un sencillo esquema para analizar los argumentos de eficacia en la discusión parlamentaria de las leyes [4] y lo aplicaré, siquiera a modo de ejemplo, a los debates sobre la modificación del código civil español en materia de matrimonio [5].

\section{LA EFICACIA DE LA LEGISLACIÓN}

Con la expresión «eficacia de las leyes», o «de la legislación», solemos referirnos a ideas diversas, aunque relacionadas entre sí. Pienso que cabría distinguir, por lo menos, seis grandes variantes de eficacia, que pueden manifestarse en diferentes combinaciones y proporciones según cada tipo de ley: el cumplimento, la aplicación, la movilización, la efectividad, la eficiencia y la eficacia simbólica.

El concepto de eficacia (social del derecho) designa, en primer lugar, la realización fáctica, observancia o cumplimiento de las conductas prescritas jurídicamente — queda circunscrito, por tanto, a las normas de obligación: mandatos y prohibiciones-. A pesar de que tendemos a manejarla como una categoría unitaria, esta idea puede analizarse de una forma más circunstanciada. Cabría distinguir, por ejemplo, entre la eficacia como «correspondencia» con las prácticas sociales, como mero «acatamiento», o como «cumplimiento» consciente de las normas jurídicas (NAVARRO, 1990: 16); y en esta línea podrían indicarse también otras modalidades subjetivas de eficacia según la clase de motivaciones subyacentes (DE BAKKER, 2003: 221 y ss.). Las prescripciones son eficaces asimismo cuando se aplican regularmente, aun en contra de la voluntad de sus destinatarios o, en su caso, cuando su incumplimiento es sancionado; esta variante puede denominarse eficacia como aplicación (HIERRO, 2003: 139). En una tercera acepción, la eficacia social incluye la movilización o invocación del Derecho (COTTERRELL, 1993: 211), y el concepto se extiende, más allá de la observancia de mandatos y prohibiciones, al «uso» de permisos y de normas que confieren poderes (vid. BLANKENBURG, 1977: 37, y DELGADO, 2006: 198). El cuarto significado es el de efectividad ${ }^{1}$, eficacia «política» (PRIETO, 2005: 85) o eficacia «como éxito» (HIERRO, 2003: 160), que designa la me-

\footnotetext{
${ }^{1}$ Cuando el término «efectividad» es empleado para designar el grado de cumplimiento o aplicación, se llama «eficacia» al grado de consecución de los fines de la norma; véase, por ejemplo, MADER, 2002: 109, o DíEZ RIPOLLÉS, 2003: 95.
} 
dida del logro de los cambios sociales pretendidos o el grado de satisfacción de los objetivos y resultados perseguidos con el Derecho. Aunque se puede estudiar por separado (GRIFFITHS, 2005: 8, y MADER, 2002: 111), adscribiré a esta acepción la idea de los efectos, las consecuencias o el impacto que provocan las normas jurídicas en la sociedad (FRIEDMAN, 1975: 48). Y con la efectividad pueden vincularse a su vez otras dos variantes de eficacia.

Es posible también entender la eficacia del Derecho como eficiencia. El análisis económico del Derecho ha apuntado la eficiencia, en el sentido de maximización de la riqueza, como un criterio normativo para orientar la creación y aplicación de leyes, pero aquí manejaré otras dos lecturas de este concepto ${ }^{2}$. Por una parte, entenderé la eficiencia de un modo más corriente o menos técnico: de entre dos medios idóneos para alcanzar un fin, uno será más eficiente que otro si comporta menos costes en esfuerzo, tiempo, recursos o dinero (HIERRO, 2003: 172). Analizar la eficiencia como menor coste presupone la conmensurabilidad de costes y beneficios y, por tanto, es problemático en presencia de diferencias axiológicas. La otra acepción, que llamaré eficiencia procedimental u organizativa, resulta de aplicar la ratio coste/beneficio a los procesos jurídicos institucionalizados (KIßLER, 1984: 151-152). En el parlamento, el criterio de la eficiencia expresaría el objetivo de optimizar los costes de la tramitación legislativa (votaciones, reuniones, comparecencias, etc.); y en la organización judicial mediría el logro de la mayor cantidad de decisiones no recurridas y ejecutadas con el mínimo coste procedimental posible (tiempo de deliberación, duración de las sesiones, número de instancias, etc.).

La última acepción que consideraré es la de eficacia simbólica. En la manera habitual de entender esta modalidad, decimos que una ley sólo despliega efectos simbólicos, en tanto que contrapuestos a los efectos «reales», si carece de mecanismos adecuados de aplicación y ejecución que aseguren la realización social de su contenido normativo ${ }^{3}$. En tal caso, la legislación cumple básicamente una función expresiva, de fijación y manifestación pública de (símbolos que encarnan) ciertos valores o propósitos. Pero del carácter simbólico de la legislación se puede hablar también para designar la función semiótica o comunicativa que cumplen algunas leyes al establecer un vocabulario jurídico y un conjunto de topoi que posibilitan y orientan el desarrollo ulterior de prácticas discursivas de construcción del significado del Derecho (WITTEVEEN y vAN KLINK, 1999: 131, y VAN DER BURG, 2005: 252). Desde este ángulo, los elementos simbólicos de la legislación son recursos argumentativos que los diferentes actores sociales, políticos y jurídicos podrían emplear para consensuar aplicaciones e interpretaciones puntuales de las normas en casos concretos. Y cuando este proceso se articula discursivamente, los destinatarios de la legislación tenderían a actuar motivados por di-

\footnotetext{
${ }^{2}$ Sobre la relación entre eficiencia y Derecho puede verse, por ejemplo, HIERRO, 2002, o CALSAMIGLIA, 1989.

${ }^{3}$ KINDERMANN, 1988: 230 y ss., señala tres tipos de legislación simbólica: aquella que trata de reforzar ciertos valores y refleja la ideología dominante o la constelación de fuerzas y grupos de poder dentro de la sociedad; la legislación «coartada» o «pretexto», que sólo busca promover la confianza en el sistema jurídico-político y demostrar su capacidad para hacer frente a las necesidades colectivas; y la legislación que fija compromisos «dilatorios» y aplaza o pacifica temporalmente determinados conflictos sociales. DíEz RIPOLLÉs, 2002: 88 y ss., ofrece una tipología más pormenorizada de normas simbólicas en el ámbito del Derecho penal. Cfr. también BLANKENBURG, 1977: 44 y ss., y COTTERRELL, 1993: 91-92.
} 
chos elementos y, por tanto, a hacerlos eficaces y efectivos en la práctica. Sobre esta forma de entender la eficacia simbólica volveré después con más detalle.

\section{EFICACIA Y RACIONALIDAD LEGISLATIVA}

La historia del interés por la eficacia de la ley es antigua. El tema de la eficacia atañe a la relación entre Derecho y sociedad, en especial a las intervenciones jurídicas en la realidad social, así que todas las concepciones antiformalistas y sociologistas del Derecho, desde el siglo XIX, han subrayado su importancia. También para la ciencia y la técnica legislativas, en los últimos años al menos, el conocimiento de las relaciones o áreas sociales que se regulan, así como la evaluación de las consecuencias de las leyes vienen siendo asuntos prioritarios (КÖСK, 2002: 8-9). En el Estado del bienestar, con la explosión del Derecho regulativo y las sucesivas oleadas de juridificación, las cuestiones de eficacia en sentido amplio, en especial las relativas a la implementación ${ }^{4}$, han cobrado incluso una relevancia teórica y política fundamental (CALVO, 2005: 44 y ss.). Y si con el intervencionismo estatal se consolidaba una tipo de legitimación «basado en la eficacia para satisfacer necesidades o demandas sociales» (CAPELLA, 1997: 195), ya en época más reciente la crisis del llamado instrumentalismo jurídico ha reavivado el debate de la eficacia, sobre todo en relación con las estrategias regulativas en la sociedad compleja (VAN AEKEN, 2005: 72). Esta evolución perfila el contexto en el que abordaré la relación entre eficacia y racionalidad legislativa.

\subsection{La multidimensionalidad de la racionalidad legislativa}

Decir que la razón práctica es multidimensional resulta ya un lugar común. Esta idea se ha instalado en el campo jurídico, donde la racionalidad ${ }^{5}$, tanto en la formación como en la aplicación del Derecho, tiende a evaluarse hoy según parámetros «compuestos». Los planos o dimensiones de análisis varían según el modelo teórico ${ }^{6}$, pero suelen responder - me ciño ahora a la legislación — a alguna composición de criterios jurídicos, teleológicos, políticos y morales 7 . Un ilustrativo ejemplo ofrece LA SPINA (1989: 179 y ss.), para quien las decisiones legislativas han de integrar i) la racionalidad formal, relativa a la sistematicidad y la certeza del ordenamiento jurídico; ii) la racionalidad instrumental o respecto al fin, en un sentido que comprende el análisis de la eficiencia y las consecuencias sociales de la ley; iii) la racionalidad material o axiológica, y iv) la racionalidad política o razonabilidad, que jugaría el rol de una meta-racionalidad llamada a lograr una combinación razonable de las facetas anteriores.

De entre las dimensiones de racionalidad relevantes para estudiar la legislación, la racionalidad con arreglo a fines (WEBER, 1969: 20) es la que normalmente asociamos

4 Véase, sobre este concepto, BLÁZQUEZ y MORATA, 2005, o INGRAM, 1990.

5 Uso el término «racionalidad» en el sentido de «razonabilidad»; cfr. ATIENZA, 1987, o ALEXY, 2008.

${ }^{6}$ Cfr., por ejemplo, WróBlEWSKI, 1990: 100 y ss., y TUORI, 2002: 134 y ss.

7 Véase MARCILLA, 2005: 275 y ss., y, sobre la correlación entre formas de racionalidad y de argumentación en el proceso de legislación, HABERMAS, 1998: 225 y ss. También en campos afines al legislativo, como el análisis de políticas públicas, se considera necesario atender a diferentes dimensiones de racionalidad (PÉREZ SÁNCHEZ, 2005: 8). 
con temas de eficacia. Pero la conexión entre eficacia y racionalidad de las leyes resulta más compleja si tenemos en cuenta, de un lado, las diversas modalidades de eficacia y cómo se coordinan entre sí y, por otro, las tensiones y solapamientos entre los distintos niveles de racionalidad aplicables a la legislación. El de ATIENZA es uno de los modelos que mejor captura esta complejidad, de manera que me serviré de él para introducir el papel de la eficacia en la racionalidad legislativa.

AtienZA (1997: 27 y ss.) distingue cinco planos o niveles de racionalidad en la legislación: R1) la racionalidad lingüística o comunicativa, en cuanto que el emisor de la ley tiene que transmitir con éxito un mensaje normativo al destinatario; R2) la racionalidad jurídico-formal o sistemática, ya que toda ley ha de insertarse coherente y consistentemente en un ordenamiento jurídico que preexiste a su promulgación; R3) la racionalidad pragmática, que expresa el grado en que las leyes cobran eficacia «real» o son cumplidas u observadas; R4) la racionalidad teleológica o instrumental, esto es, la idoneidad de la ley para alcanzar los objetivos que persigue; y R5) la racionalidad ética, en tanto que los fines y contenido de la ley presuponen valores que deberían ser éticamente justificables, es decir, legítimos. Y a estos cinco niveles añade luego una dimensión transversal R6) que llama eficiencia, y que cifra en el logro de un «equilibrio óptimo» (ATIENZA, 1997: 93) o «ajuste razonable» (AtIENZA, 2005: 312) entre ellos ${ }^{8}$.

\subsection{La eficacia en el modelo de legislación de Atienza}

En este modelo aparecen, pues, dos formas de racionalidad ligadas a la eficacia (ATIENZA, 1997: 36-38): la pragmática (R3) y la teleológica (R4). La primera mediría el grado de realización práctica del contenido prescrito por la ley, así como la influencia de ésta en la conducta de sus destinatarios; en este sentido, una ley es irracional cuando fracasa como directiva. Aunque esta categoría parece pensada para mandatos y prohibiciones (eficacia como cumplimiento y aplicación), puede extenderse fácilmente a permisos y normas que confieren poderes (eficacia como movilización). La racionalidad teleológica, por su parte, viene referida a la consecución de los objetivos y fines de la ley (efectividad) ${ }^{9}$, así como a su impacto social; una ley es teleológicamente irracional en la medida en que no produzca efectos, produzca efectos negativos o no produzca los efectos deseados o previstos por el legislador — sean o no efectos «declarados»—. Para analizar cómo operan estos niveles de racionalidad, ATIENZA (1997: 42) propone el siguiente cuadro ${ }^{10}$ :

\footnotetext{
${ }^{8}$ Nótese que ATIENZA no entiende aquí la eficiencia en su acepción de «menor coste» —en este sentido es un aspecto interno de la racionalidad instrumental—, sino que la define en términos de razonabilidad.

9 Aquí habría que agregar la eficiencia entendida como menor coste: como anota CALSAMIGLIA, 1993: 172, desde el punto de vista de la racionalidad teleológica, «una ley bien hecha es aquella que consigue su objetivo con el mínimo costo», mientras que sería irracional «si asigna ineficientemente los recursos».

${ }^{10}$ Hierro, 2003: 168-170, plantea un esquema equiparable para la medición del éxito de las normas.
} 


\section{FIGURA 1}

Esquema para el análisis de eficacia y efectividad (ATIENZA)

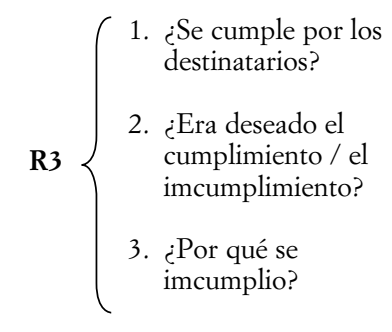

$\mathbf{R 4}\left\{\begin{aligned} \text { 4. } & \text { ¿Tiene efectos } \\ & \text { apreciables? } \\ 5 . & \text { ¿Tiene los efectos } \\ & \text { declarados? } \\ \text { 6. } & \text { ¿Tiene los efectos } \\ & \text { previstos? } \\ 7 . & \text { ¿Son efectos } \\ \text { positivos (desables } & \text { o deseados)? }\end{aligned}\right.$
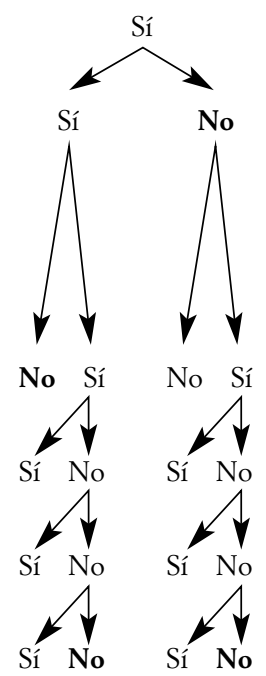
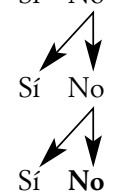
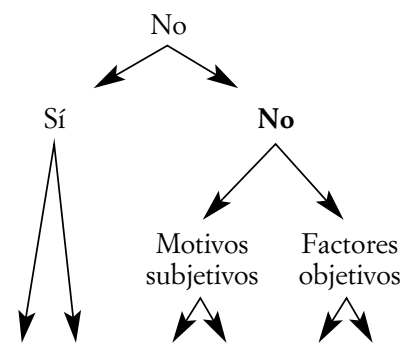

No Sí

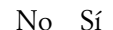

No Sí

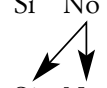

Sí No

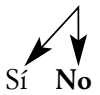

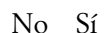
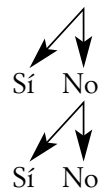

Sí No

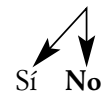

El cuadro permite identificar diferentes tipos de irracionalidad legislativa —señalados en negrita- En el nivel de racionalidad pragmática existirían dos problemas básicos: que la ley se cumpla cuando se pretendía que no se cumpliera y, al revés, que se incumpla cuando se buscaba su cumplimiento. El primero puede aparecer en aquellos casos de legislación simbólica en que las normas se promulgan sin auténtica pretensión de que cobren eficacia real. El segundo sería el supuesto común de ineficacia o falta de cumplimiento —o movilización - de las leyes, que ATIENZA (1997: 45) atribuye a dos clases de factores: subjetivos o de motivación, como la ausencia de sanciones negativas y positivas adecuadas, y objetivos, en particular las carencias de financiación o de cobertura organizativa.

En el plano teleológico, cabría destacar seis supuestos de irracionalidad (ATIENZA, 1997: 46 y ss.): i) leyes sin efectos apreciables —algo infrecuente si contamos su efecto simbólico- que sólo contribuyen a la polución legislativa; ii) el cumplimiento deseado de una ley, con efectos apreciables (e. g., una norma muy estricta sobre tasas de alcoholemia que se aplica, aunque con laxitud), pero ni previstos ni positivos (no logra su objetivo: reducir muertes); iii) leyes que se cumplen o aplican, cuando ello no se pretendía en verdad, y que provocan efectos no declarados, imprevistos y negativos (e. g., una norma que se cumple en forma de huelga de celo); iv) el incumplimiento deseado de la ley que trae efectos no declarados, ni previstos ni positivos (e. g., cuando se fija «simbólicamente», sin articular un sistema de sanciones adecuado, un salario mínimo para empleados domésticos, y no sólo se incumple, sino que provoca que los empleadores dejan de asegurar a los empleados para no tener que afrontar el aumento de salario); v) un incumplimiento no deseado, por motivos subjetivos, que comporta efectos 
no declarados, ni previstos ni positivos (e. g., se regula un estricto horario laboral, pero sin sanciones ni incentivos, por lo que se incumple y no reduce el absentismo); y, por último, vi) el incumplimiento no deseado que responda a factores objetivos y ocasione efectos no previstos ni positivos (e.g., una ley que para democratizar las universidades cree órganos de gobierno masificados: si éstos no son operativos, la toma de decisiones queda en manos de camarillas informales y acaba desvirtuada).

El esquema de ATIENZA ofrece ya alguna pauta para analizar y estructurar la discusión parlamentaria sobre eficacia. En especial, habría que ver si los representantes políticos se plantean esa batería de preguntas al debatir las leyes y, en su caso, qué respuestas aportan: qué estimaciones hacen del nivel de cumplimiento o de litigiosidad, cómo valoran el coste económico, el impacto o las eventuales consecuencias de las normas en la sociedad, etc. Todas estas consideraciones suelen agruparse teóricamente bajo la rúbrica de la evaluación legislativa ${ }^{11}$. Las metodologías y prácticas de evaluación retrospectiva (expost) de leyes están más consolidadas, pero los cálculos y análisis ex ante, ya sean prospectivos y previos a la redacción del proyecto jurídico o posteriores a ésta, también son frecuentes - a veces incluso obligatorios-, con lo que los parlamentarios suelen tener ocasión de pronunciarse sobre ellos. La teoría de la evaluación legislativa, en ese caso, puede suministrar criterios para organizar y enjuiciar el contenido de sus argumentos.

\subsection{Relaciones entre niveles de racionalidad legislativa}

Desde el punto de vista de una teoría multidimensional de la legislación racional, y de cara al análisis argumentativo, resulta interesante mostrar cómo se relacionan R3 y R4 con los demás niveles de racionalidad y, en particular, qué tipo de tensiones median entre unos y otros. Esto podría ayudar a establecer el peso de los argumentos de eficacia en el proceso de justificación de la ley.

$R 1-R 3 / R 4$. Una primera tensión puede darse entre la eficacia o la efectividad de la ley y su configuración lingüística. La variante más común de este conflicto surge cuando las imprecisiones o errores de formulación abren márgenes de inseguridad que dificultan el cumplimiento, la aplicación o la movilización de la norma, o perjudican los fines que ésta persigue ${ }^{12}$. En otra variante, lo que ocasiona el conflicto es la legislación simbólica, en el sentido de normas hechas para no ser cumplidas o no producir los efectos declarados. A veces, la ambigüedad o la vaguedad proporcionan «un medio para lograr la racionalidad pragmática y teleológica»; y por eso, que las leyes sean «intencionadamente oscuras e imprecisas» puede significar, sencillamente, que la racionalidad lingüística se supedita a la eficacia y efectividad (ATIENZA, 1997: 59). Un enfoque multidimensional de la legislación habría de indicar, por tanto, cuándo la eficacia social o

11 Véase KARPEN, 2002; BÖHret y KonZendorf, 2001; Rossi et al., 2003; RADAELli, 2001; COUNCIL OF Europe, 2001; MONTORO, 2001; FIGEROA, 1995; OsÉs, 1994, o KÖNIG, 1989; cfr. DíEZ RIPOLLÉs, 2003 : 59 y ss.

${ }^{12}$ Con todo, los márgenes de inseguridad son inherentes al Derecho: «aunque los creadores de textos jurídicos tratan de incidir en la conducta» de los ciudadanos y funcionarios «fijando por escrito las reglas que quieren» que utilicen «como razones para su acción, esos textos atraviesan una cadena de relaciones en la que son constantemente reinterpretados y usados para generar reglas diferentes»; el mensaje legal, cuando llega por fin a su destino, puede ser una «parodia respecto de su inicial precisión jurídica» (SAMPFORD, 1989: 235, 254). 
los fines de la ley se consiguen mejor con normas abiertas - como veremos en seguida, WiTTEVEEN arma alrededor de esta idea su modelo de legislación.

R2-R3. Señala ATIENZA (1997: 60) que entre racionalidad jurídico-formal y eficacia de la ley existe una «relación de independencia bastante acusada». Que las normas sean más o menos eficaces no depende, en principio, de su grado de sistematicidad; factores más decisivos son las motivaciones individuales y los filtros sociales. Pero lo cierto es que, en tiempos de hipertrofia y desorden normativos, parece esencial atender a este punto: cuantas más normas contiene un sistema jurídico, mayor es el riesgo de que los afectados por ellas las desconozcan o las incumplan, de que colidan unas con otras y generen dificultades de interpretación, y también más difícil y costoso resulta fiscalizar su cumplimiento (vid. vAN HOECKE, 2002: 79). Asimismo, en los ordenamientos jurídicos compuestos, como el español (que ha de integrar legislación europea, estatal y autonómica), la racionalidad sistemática cobra una valencia adicional, relativa a la distribución de competencias, que también puede condicionar la eficacia de aplicación y, sobre todo, la efectividad.

R2-R4. La relación entre la racionalidad sistemática y la efectividad de las leyes es una de las claves en el análisis de los argumentos de eficacia. Entre estos dos planos parece existir un conflicto irreductible, y la mayoría de estudios legislativos subrayan la contraposición entre ambos: en la fase de elaboración de las leyes suelen brotar graves «tensiones entre la voluntad política y las recomendaciones técnicas» (MARCILLA, 2005: 297). En cualquier caso, conviene recordar que un déficit de racionalidad jurídico-formal, como el que aqueja por ejemplo al Derecho regulativo, no necesariamente conduce a mayores cotas de efectividad ni facilita la consecución de los objetivos de la ley.

R3-R4. También es posible analizar las relaciones entre las diferentes modalidades de eficacia, en especial entre los niveles de observancia o de uso de la ley (R3) y el logro eficiente de los fines perseguidos (R4). De hecho, solemos estudiar estos dos planos de racionalidad conjuntamente, como si hubiese un nexo de continuidad entre ambos $^{13}$. Pero hay que considerar además eventuales tensiones: la movilización masiva de ciertas normas de prestación, pongamos por caso, podría colapsar el aparato burocrático del Estado y terminar frustrando los propósitos legislativos; y puede ocurrir asimismo que una ley se incumpla y genere con ello efectos positivos que no fueron previstos por el legislador.

$R 5-R 3 / R 4$. Los problemas de eficacia y efectividad parecen desligados de consideraciones ético-normativas: el grado de cumplimiento del Derecho y de realización de sus objetivos son independientes de su justificación o su corrección moral (ATIENZA, 1997: 63). Ahora bien, la argumentación sobre efectividad, en particular cuando atañe a las consecuencias y al impacto social de las leyes, está siempre impregnada de valoraciones ${ }^{14}$. Las cuestiones empíricas e instrumentales que surgen al legislar no pueden separarse de las normativas fácilmente y, aunque por lo general los fines de la ley se for-

13 «Si se estima racional que la legislación se cumpla es quizá porque, en principio, la eficacia se supone un presupuesto de la efectividad» (Marcilla, 2005: 278); parecidamente, DíEz RIPOLLÉs, 2003: 95, aunque bajo otra nomenclatura y apartándose del enfoque de ATIENZA sobre las racionalidades pragmática y teleológica.

14 Véase Feteris, 2002: 355; Marcilla, 2005: 305, o Calsamiglia, 1993: 174. 
mulan en términos amplios y muchas veces no resultan controvertidos, el debate acerca de los medios legislativos más idóneos suele revelar conflictos axiológicos de fondo.

\section{ARGUMENTACIÓN Y CAPACIDAD REGULATIVA DEL DERECHO EN LA SOCIEDAD COMPLEJA}

Hace ya tiempo que el análisis de los factores que condicionan la incidencia social y la capacidad regulativa del Derecho estatal en las sociedades complejas puso de relieve la necesidad de revisar el llamado instrumentalismo jurídico y los modelos cibernéticos de «mandato-y-control» aparejados con él (TEUBNER, 1986, y BALDWIN, 1997). Pese a la variedad de soluciones teóricas que se han propuesto en los últimos años, cabría decir que todas comparten una sencilla tesis de base: la regulación de las áreas o relaciones sociales por medio del Derecho no puede ya imponerse «desde fuera» ni verticalmente, sino que han de articularse formas cualificadas de colaboración o participación de la sociedad en los procesos de creación, interpretación e implementación de las normas estatales ${ }^{15}$. En esa dirección apuntan, por citar algunos, los estudios sobre la formación negocial y concertada de la ley (LIPARI, 1990; MAESTRO, 1991, y BLACK, 1998), la teoría del Derecho reflexivo (TEUBNER, 1983), la del funcionamiento social de las normas jurídicas (GRIFFITHS, 2003), o los diversos modelos de responsive law (NoNET y SELZNICK, 1978; AyRES y BRAITHWAITE, 1992; BIZER et al., 2002, y BLACK y BALDWIN, 2007). De esta literatura acerca de la capacidad regulativa del Derecho interesan ahora los enfoques que la conectan con la argumentación durante las fases de producción e interpretación del Derecho. Así lo hace el modelo de «legislación comunicativa» que propone WITTEVEEN $(1994,1999,2005)$ a partir de una reconsideración de la eficacia simbólica de las leyes.

\subsection{Dimensiones de la comunicación legislativa: mensajes y símbolos}

Existe cierto acuerdo en que las leyes suelen poseer una doble naturaleza, instrumental y simbólica (KINDERMANN, 1988: 229, y BLANKENBURG, 1977: 44): tratan de dirigir u orientar la conducta de sus destinatarios a fin de conseguir algún objetivo político, al tiempo que encarnan y señalizan públicamente determinados contenidos éticos, morales o ideológicos (aunque también puedan elaborarse leyes con este solo propósito). WitTEVEEN replantea esa idea en términos de dimensiones comunicativas: la legislación consistiría unas veces en la transmisión de mensajes normativos — reglas, si se prefiere-, y otras sería una actividad constructiva en la que se negocia un significado compartido para cierto texto o «símbolo». Y mientras que un caso responde al ideal de la seguridad jurídica y del imperio de la ley, al otro le subyace un ideal democrático y deliberativo. La dimensión textual o simbólica se reflejaría en conceptos jurídicos indeterminados y en normas abiertas, programáticas o «aspiracionales» — digamos, en los principios- Este tipo de comunicación legislativa ya no transmite «significados

15 Por ejemplo, KIßLER, 1984, o GRIFFITHS, 2003, insisten en que la génesis de las normas jurídicas determina su status posterior en las prácticas sociales, así como la medida y el modo en que será observada; es decir, la manera más o menos participativa en que se crea el Derecho ya decide sobre su eficacia y efectividad. 
normativos»: abre la posibilidad de construirlos interpretativamente (WITTEVEEN, 1994: 330). Pues bien, la tesis de WiTTEVEEN es que la dimensión simbólica del Derecho, bajo ciertas condiciones, constituye un mecanismo regulativo muy útil: no es una fuente de problemas de eficacia y efectividad, sino una oportunidad para resolverlos. Y eso es lo que habría pasado por alto el instrumentalismo jurídico, demasiado centrado en la transmisión exacta de los mensajes normativos y en su coercibilidad. WITTEVEEN cree que muchas de las dificultades de la legislación para generar efectos en la sociedad derivan justamente de carencias «simbólicas». Los enfoques cibernéticos presuponen la autoridad y legitimidad de las leyes, pero no explicarían cómo generar la motivación para que sean aceptadas: parecen dar por hecho que los destinatarios las cumplirán movidos por cálculos utilitaristas (WITTEVEEN, 1999: 36). Sin embargo, en los entornos sociales que tratan de juridificarse suele haber prácticas, normas y valores que preexisten a la legislación, y ésta ha de sintonizar con ellos de algún modo si quiere cobrar eficacia real —una intervención directa podría ser rechazada u ocasionar efectos indeseados- . Ahí entra en juego la función regulativa de las normas simbólicas: cuando su formulación legal y su interpretación y concreción social se configuran como procesos inclusivos de argumentación, es más fácil que dichas normas sean reconocidas y aceptadas por sus destinatarios, y que éstos, por tanto, las incorporen a sus prácticas cotidianas como razones para la acción ${ }^{16}$. Éste es el sentido en el que despliegan, siquiera mediatamente, efectos regulativos.

\subsection{La «estrategia legislativa reflexiva»}

WiTTEVEEN (1999: 49) no quiere decir que estas dimensiones sean incompatibles: una ley puede incluir tanto elementos reglados («significantes») como simbólicos. Ahora bien, para que desarrolle toda su capacidad regulativa — para que resulte eficaz y efectiva- es preciso equilibrarlos. Ambas facetas han de integrarse en un modelo de legislación «sinfónica» que logre su combinación óptima. Esto supone un momento de «reflexividad» de parte de todos los actores del proceso legislativo, de manera que, como participantes en una deliberación, puedan decidir qué modalidad comunicativa, el mandato o el símbolo, es preferible en cada caso. Para clarificar esta tesis, WiTTEVEEN (2005: 27) introduce la noción de «estrategia legislativa reflexiva». Esta estrategia consistiría en la discusión sobre qué debe hacerse para asegurar la eficacia social y el logro de los objetivos legales actualizando los ideales de democracia e imperio de la ley simultáneamente. Sería en este «metanivel» del debate legislativo, pues, donde los actores del proceso de formación de la ley han de resolver cuándo ésta tiene que formu-

16 La legislación simbólica, entonces, no se diferenciaría de la instrumental por no influir en la conducta, sino por el modo en que influye y el tipo de conducta a que afecta (KINDERMANN, 1989: 257). Como observa DíEz RIPOLLÉs, 2002: 69-70, en relación con el Derecho penal, «la desacreditación [...] de los efectos simbólicos es apresurada, pues [...] no sólo están en condiciones de proteger bienes jurídicos a través de la prevención de comportamientos sino que, además, resultan imprescindibles» para hacerlo; convendría por ello «sustituir el término "simbólico" por otro menos prejuicioso» y asumir que toda acción legislativa puede tener «funciones instrumentales, expresivas e integradoras»; quien sostiene que los elementos «expresivo-integradores» «son incapaces de proteger bienes jurídicos a través de la prevención de comportamientos» cae en el error de suponer «que la producción en los ciudadanos de determinados estados de ánimo o representaciones mentales [...] no tiene consecuencias directas sobre su actuar» o que su repercusión es tan limitada «que, bien sólo puede jugar un papel muy secundario, bien debe admitirse como un efecto indeseable». 
larse claramente mediante reglas y cuándo como expresión simbólica de normas compartidas por una comunidad ${ }^{17}$. Aunque no es fácil apuntar criterios que justifiquen la preferencia por una u otra modalidad legislativa, WiTTEVEEN (2005: 40-41; WITTEVEEN y VAN KLINK, 1999: 135) identifica tres situaciones en que sería apropiado emplear la táctica simbólica y participativa de las normas abiertas: i) cuando el legislador no posee conocimiento técnico suficiente para fijar reglas precisas y claras; ii) cuando la materia sobre la que quiere intervenir es demasiado compleja o cambiante como para ser regulada con detalle; y iii) cuando el tema legislado tiene implicaciones ideológicas o ético-morales fuertes. Se dirá que, en este último supuesto, la táctica simbólica no hace sino posponer la solución de conflictos ideológicos, o que cumple, a lo sumo, una función pacificadora. Pero WITTEVEEN está convencido de que concede a los destinatarios de la ley la oportunidad de cambiar gradualmente sus actitudes a través de procesos de diálogo, ya que pone a su disposición un vocabulario legal y un conjunto de principios y topoi con los que pueden argumentar y especificar, en casos concretos, soluciones puntuales para dichos conflictos de fondo. Y en torno a esta idea vertebra su modelo de legislación comunicativa.

\subsection{Hacia una legislación «comunicativa»}

En este análisis late un intento de concebir la labor legislativa como una forma de creación constitucional: las constituciones vendrían a ser lo más próximo a las leyes sinfónicas. Ahora bien, WitTEVEen (1999: 66 y ss., y 2005: 35 y ss.) confiere al término constitución un significado amplio que abarca cualquier ley que desempeñe «funciones constitutivas» en un campo social. Y las «constituciones» de esta índole no sólo regulan ámbitos sociales donde ya existen comunidades locales, sectoriales o funcionales, sino que pueden ser igualmente el impulso para que, en un área social o ante un problema determinado, nazca una «comunidad interpretativa» de «ciudadanos» ${ }^{18}$. La clave del éxito regulativo, en uno u otro caso, sería involucrar a todos los afectados en un proceso argumentativo de formación y aplicación de las normas. Quizá donde mejor se aprecia la similitud entre constitución y ley sea en la dimensión simbólica, y en ella se centra WITTEVEEN para explicar cómo opera la «legislación comunicativa». Esta modalidad de regulación comprendería dos estadios: el momento constitucional, o de fijación del texto legal, que junto a las decisiones sobre el contenido comprende el debate acerca de la táctica legislativa apropiada; y el conjunto de prácticas discursivas a través de las que una amplia comunidad de intérpretes desarrolla y determina el significado de dicho texto en contextos reales (WITTEVEEN y VAN KLINK, 1999: 131) ${ }^{19}$. En la primera fase, los actores tienen que acordar sus «aspiraciones compartidas» y ser capa-

17 Una idea muy próxima a ésta puede verse en HABERMAS, 1998: 524-525: «el trato legislativo con el Derecho exige del legislador parlamentario que tome primero decisiones en un metanivel, es decir, que tome decisiones acerca de si ha de tomar decisiones, de quién habría de tomarlas en su lugar y, en caso de que quiera decidir, qué consecuencias se siguen para la elaboración y desarrollo legítimo de sus programas». En la misma línea discurre la noción de «metanomismo» que propone VAN AECKEN, 2005: 86.

${ }_{18}$ Esta idea de constitución se asemeja bastante al concepto de super-statute (ESKRIDGE y FEREJOHN, 2001).

19 Parejamente analiza Aguiló, 2006: 13, los conceptos «esencialmente controvertidos» o «incompletamente teorizados» de la constitución, que formarían parte de una estrategia de regulación compleja y consensual: «sirven para poner en el primer plano el consenso básico a partir del cual puede construirse una práctica jurídico-política centralmente discursiva o deliberativa». 
ces de proyectarlas en la ley (WITTEVEEN, 1999: 70). Han de expresar, en forma aceptable para todos, los valores y principios básicos de la comunidad o del área social en que la ley debe surtir efecto, así que tenderán a prescindir de consideraciones contextuales y a preferir formulaciones abiertas (el funcionamiento de las leyes-constitución no seguiría pautas cibernéticas). Este modo simbólico de legislar perfila un marco agonístico para disputas interpretativas que tendrán que ventilarse en vista de situaciones problemáticas y casos difíciles. Cada vez que se haya de actualizar el texto «constitucional» saldrá a la luz la constelación de fuerzas, intereses y convicciones ético-morales de la sociedad en ese momento. Pero en este segundo estadio de la legislación comunicativa, los principios y tópicos oficialmente asumidos al elaborar la ley estarían ya a disposición de los actores sociales, y les permitirían armar argumentos para reconstruir su significado. Esta tesis presupondría, pues, que una deliberación social inclusiva durante la «fase agonística» conducirá a los destinatarios a consensuar aplicaciones puntuales del texto simbólico y les motivará a orientar su conducta en las «aspiraciones oficiales» previamente asumidas en el momento constitucional. En ello residiría, a la postre, la eficacia simbólica de la legislación con la que WITTEVEEN propone remediar las carencias del instrumentalismo ${ }^{20}$.

\section{JUSTIFICACIÓN RACIONAL Y EFICACIA DE LA LEGISLACIÓN: UN ESQUEMA DE ANÁLISIS}

Las cuestiones relativas a la eficacia son, según hemos visto, parte esencial de la teoría de la legislación racional; y la reconsideración de la eficacia simbólica (como una táctica para mejorar la capacidad regulativa del Derecho), a su vez, ha permitido apuntar la relevancia de la argumentación en este contexto. Intentaré ahora esbozar un esquema para analizar el papel de la eficacia dentro de la argumentación legislativa, o sea, para estudiar cómo están fundamentadas las leyes en cuanto a la eficacia —si al debatirlas se discuten cuestiones como su impacto y efectos sociales, su coste económico o su implementación; si se aportan datos estadísticos e información empírica y sociológica relevante; o si se valora la reacción de los destinatarios- - Se trataría de dar cuenta, en suma, de cómo se inserta la eficacia en el discurso de justificación legislativa.

${ }^{20}$ Para analizar si una ley «comunicativa» logra cambios sociales, las prácticas discursivas han de verse como procesos que evolucionan en el tiempo (WITTEVEEN y VAN KLINK, 1999: 133). Desatender este aspecto dinámico lleva a pensar que las intenciones del legislador no influyen en las áreas que pretendía regular, pero evaluar la eficacia simbólica cuando apenas ha sido promulgada la ley sería engañoso. WITTEVEEN asume que las normas aspiracionales buscan transformar la mentalidad social, y que cambios de esta índole son difíciles; pero cree que los límites de la legislación instrumental pueden superarse si el legislador diseña un marco argumentativo dentro del cual los actores oficiales y sociales puedan traducir a la práctica los propósitos de la legislación; un marco donde las medidas coactivas dejen paso a las pedagógicas y nuevas formas institucionales (comisiones éticas, agencias especializadas, etc.) accesibles a todos dinamicen las prácticas discursivas en la sociedad y promuevan foros de debate para ciudadanos y expertos. En esta fase se especificaría el sentido de los ideales compartidos fijados en la ley de modo que los ciudadanos encontrasen en ellos una motivación racional para su conducta. 


\subsection{Cuestiones preliminares}

Aparte de las dificultades que entraña el análisis de la argumentación parlamentaria en general (SIECKMANN, 2005, y STEINER et al., 2004), estudiar los argumentos de eficacia en el contexto de la legislación suscita al menos cuatro problemas. El primero afecta a la delimitación del ámbito de análisis. Uno pensaría que el lugar indicado para encontrar esa clase de argumentos son los materiales y trabajos preparatorios - como los informes sobre viabilidad económica o necesidades de implementación que acompañan a los proyectos legislativos-, que también forman parte del proceso institucionalizado de justificación de las leyes. Pero aquí me ceñiré a la faceta de discusión argumentativa dentro de ese proceso, es decir, al debate parlamentario ${ }^{21}$. Se objetará que esta delimitación condiciona el análisis: la evaluación de la ley sería una tarea para los expertos, y correspondería a las instancias tecnocráticas que intervienen en su formación o al ministerio que elabora su proyecto. Sin embargo, que muchos parlamentarios no sean sociólogos o economistas no impide que consideren la eficacia de las medidas que van a aprobar: los resultados de la evaluación de las leyes quedan siempre sometidos al juicio político (KÖNIG, 1989: 420), y existen sin duda buenas razones para que así sea (BROCKER, 2002: 134 y ss., y OsÉS, 1994: 287). Es de suponer, además, que los informes de los especialistas habrán de reflejarse en el debate parlamentario; y éste, aun cuando carezca de sofisticación técnica, puede revelar de qué forma entienden los legisladores las funciones sociales del Derecho o, más en general, la relación entre Derecho y sociedad. La ausencia de discusiones sobre eficacia podría ser incluso un indicador de la baja calidad de la fundamentación de las leyes.

La segunda dificultad es estimar de manera fiable cuáles serán las consecuencias de las leyes: las limitaciones de las evaluaciones ex ante son muy significativas ${ }^{22}$. El problema suele señalarse a propósito de los efectos indirectos o no intencionales de una medida legislativa, y se agrava cuanto mayor sea el alcance de la evaluación, o cuando se quiere analizar la totalidad de consecuencias que puede provocar una ley. El Derecho es sólo uno entre muchos factores que confluyen en el cambio social (BLANKENBURG, 1986: 114); y, si ya resulta difícil evaluar sus efectos ex post, aún lo es más durante su proceso de creación. Pero esto no priva de utilidad a la evaluación, ni excusa a los legisladores de discutir sobre ella. Por demás, cuando la participación social en el procedimiento legislativo y en el debate público que lo circunda es amplia, el problema se reduce: los límites del análisis previo de las repercusiones de la ley se compensan escuchando a todos los afectados, de modo que los parlamentarios puedan al menos tener en cuenta múltiples visiones sobre su impacto.

En tercer lugar, puede aparecer el problema — relacionado también con la inseguridad de la evaluación ex ante- de determinar las intenciones legislativas, que han de

${ }^{21}$ Aunque conviene atender también a otros elementos de justificación de la ley, como la fundamentación de enmiendas y las exposiciones de motivos, en este trabajo los dejaré al margen. Interesa notar, por demás, que el debate parlamentario viene a ser el precipitado argumentativo de un proceso mucho más amplio que tiene lugar a escala social, antes y durante el trámite de legislación: vid. ATIENZA, 1997: 68 y ss., o DíEZ RIPOLLÉs, 2003: 18 y ss.

22 Véase, por ejemplo, KÖcK, 2002: 9 y ss.; BROCKer, 2002: 134; CALSAMIGLIA, 1993: 167; KÖNIG, 1989: 422 y ss., o KINDERMANN, 1988: 226. Para GRIFFITHS, 2005: 10, la razón esencial del fracaso del instrumentalismo es que resulta imposible armar una teoría general de los efectos indirectos de las leyes. 
compararse con el estado de cosas que prevén alcanzar las normas. Los fines se formulan a menudo en términos vagos o muy abstractos, con lo que la racionalidad instrumental de las leyes no resulta fácilmente mensurable; por otro lado, éstas no siempre persiguen un único objetivo, sino varios, a veces inconsistentes entre sí, y eso complica la valoración de los argumentos sobre la efectividad (HIERRO, 2003: 162, y FÜHR, 2002: 99 y ss.). En los casos de derecho simbólico - en el sentido tradicional de la expresión- cabría añadir la dificultad de discernir cuáles son las «verdaderas» intenciones del legislador, en contraste con las declaradas o exteriorizadas.

La última complicación tiene que ver con el hecho de que en el discurso parlamentario los distintos niveles de justificación suelen aparecer entreverados, de forma que un mismo argumento puede operar en varios simultáneamente. La concordancia de una ley con la moral positiva, por ejemplo, puede ser tanto un argumento de eficacia de cumplimiento como de legitimidad democrática; y de igual modo, en la interpretación de principios es difícil deslindar las razones jurídico-constitucionales de las ético-morales. Esa imbricación se muestra señaladamente en la discusión sobre las consecuencias sociales o empíricas de una medida —efectividad, eficiencia e impacto—, que por lo común resulta indisociable de las consideraciones axiológicas. Otra manera de expresar esta idea sería decir que la argumentación sobre efectividad tiene una vocación «atrayente»: toda ley constituye un medio para lograr un fin y, por tanto, la mayoría de argumentos esgrimidos al debatirla podrán reconducirse al plano de la racionalidad instrumental. Desde esta perspectiva, el estudio de las razones de eficacia y efectividad aboca a un examen jurídico-constitucional en el que habría de valorarse la proporcionalidad de las medidas legislativas ${ }^{23}$.

\subsection{Ideas para un modelo de análisis}

Intentaré esbozar ahora un esquema general para analizar la argumentación legislativa sobre eficacia. El esquema — que, con las oportunas adaptaciones, podría aplicarse también al conjunto de la argumentación legislativa- consta de cuatro apartados.

1. La primera cuestión es si los parlamentarios discuten sobre la eficacia de la ley y, en tal caso, en qué sentidos lo hacen. El análisis parte, por tanto, de la identificación de los argumentos de eficacia presentes en el debate legislativo. Las diferentes acepciones de este concepto sirven para clasificarlos. Es posible, así, que se tematicen aspectos relativos al cumplimiento y a sus motivos; a los mecanismos de aplicación y sanción; a la movilización de las normas; a la efectividad y las consecuencias o efectos sociales; a la eficiencia de la medida legislativa o de su tramitación; o a su valor simbólico. Desde luego, los temas y los contenidos específicos de la discusión variarán según las áreas o las materias reguladas, así como según el tipo de normas de que se trate, aunque es probable que surjan problemas recurrentes, como el coste económico o la cobertura organi-

${ }^{23}$ Como observa MADER, 2002: 115, la evaluación de efectos es «más que una herramienta tecnocrática», $\mathrm{y}$ «puede dar un nuevo sentido y una nueva significación [...] a principios constitucionales como el de igualdad ante la ley, la protección contra la arbitrariedad y, sobre todo, el principio de proporcionalidad»; así también, KÖCK, 2002: 13-14, y Montoro, 2001: 124. Un análisis de la interdependencia entre evaluación legislativa y examen de proporcionalidad puede verse en FüHR, 2002: 96 y ss. 
zativa. Debido a los caracteres del debate parlamentario, cabe esperar que los argumentos aparezcan fragmentados o sean incompletos, por lo que será preciso reconstruirlos a partir de las intervenciones de uno o varios diputados, a modo de líneas o «conexiones argumentativas» (vid. SIECKMANN, 2005: 119).

2. Los argumentos sobre la eficacia son sólo una parte de la fundamentación de la ley, y de ahí que hayan de integrarse con otro tipo de argumentos u otros niveles de justificación. Para mostrar su papel en el conjunto del debate legislativo me apoyaré en el modelo multidimensional de legislación propuesto por ATIENZA, en el que quedan adscritos a las racionalidades pragmática (R3) y teleológica (R4). Siguiendo este modelo, podríamos ver en qué medida se reflejan en la discusión parlamentaria las relaciones entre la eficacia (R3/R4) y otros planos de racionalidad legislativa (R1, R2, R5), así como la combinación que se alcanza entre ellos (R6). Esto permitiría determinar cuál es el peso relativo de los argumentos de eficacia dentro del discurso de justificación de las leyes ${ }^{24}$.

3. La relación de la eficacia y efectividad de la ley con su racionalidad lingüística podría estudiarse por separado cuando se plantea en términos de lo que WiTTEVEEN denominaba estrategia regulativa, es decir, cuando los parlamentarios discuten sobre la modalidad de comunicación legislativa más apropiada para que las normas logren realmente orientar las prácticas sociales en el sentido pretendido. Siquiera sea sólo en cierta clase de materias (Derecho regulativo, típicamente), el debate puede incluir argumentos sobre la combinación óptima entre el modo simbólico y modo cibernético de legislar - entre principios y reglas-y, por consiguiente, sobre los caracteres del campo social regulado o la probabilidad de que en él se desarrollen prácticas discursivas de interpretación y aplicación.

4. El análisis habría de considerar, en fin, la calidad discursiva o argumentativa del debate sobre eficacia ${ }^{25}$. Aquí cabe seguir y, en su caso, combinar dos líneas de trabajo. Por una parte, es posible evaluar la argumentación como tal. Existen diversas opciones teóricas al respecto: puede analizarse, por ejemplo, si la deliberación cumple exigencias generales de racionalidad, como la corrección lógica, la consistencia, la plausibilidad empírica de las premisas, la consideración de todas las razones relevantes o la ausencia de prejuicios (SIECKMANN, 2005: 124); si reúne las cualidades de la buena argumentación (JOHNSON, 2000: 180 y ss.); si satisface las reglas de la discusión crítica (VAN EEMEREN y GROOTENDORST, 2003:367 y ss.); o también cabría emplear índices de calidad discursiva expresamente concebidos para la discusión legislativa, que miden en términos formales — sin entrar en el contenido o la estructura de los argumentos- as-

${ }^{24}$ Entre planos de justificación pueden darse al menos tres tipos de relaciones: continuidad, independencia y tensión ( $c f r$. ATIENZA, 1997: 57 y ss.). Hay relación de continuidad si un aumento (o pérdida) de racionalidad en uno implica un aumento (o pérdida) de racionalidad en otro: $\uparrow R_{x} \rightarrow \uparrow R_{y}$ (o bien: $\downarrow R_{x} \rightarrow \downarrow R_{y}$ ). La relación de independencia supone que el mayor o menor grado de racionalidad en un nivel no afecta a otro: $R_{x} \wedge$ $R_{y}$, o bien: $\left(\downarrow R_{x} \vee \uparrow R_{x}\right) \wedge\left(\downarrow R_{y} \vee \uparrow R\right)$. Y existiría una tensión cuando el aumento (o la pérdida) de racionalidad en un nivel comporta una pérdida (o aumento) de racionalidad en el otro: $\uparrow R_{x} \rightarrow \downarrow R_{y}$ (o bien: $\downarrow R_{x} \rightarrow \uparrow R_{y}$ ). Las tres clases de relaciones ayudan a estudiar la estructura de la argumentación legislativa, pero quizá para la teoría de la legislación resulten más importantes las tensiones entre niveles, ya que determinan el equilibrio final entre ellos y, por ende, la razonabilidad de la ley. El análisis empírico puede servir para clarificar de qué modo operan estas relaciones en la práctica argumentativa; en particular, habrá que ver cómo aplicar este esquema a las posturas contrapuestas que pueden mantener en cada nivel los parlamentarios de uno u otro signo.

25 Se trataría de una evaluación que aplicase criterios de corrección para enjuiciar la argumentación —sobre eficacia, en este caso-y poder asignarle un mayor o menor peso justificatorio (ATIENZA, 2005: 311 ). 
pectos como la participación, la aportación de razones para las afirmaciones, el respeto al interlocutor o la presentación de jpropuestas alternativas y constructivas (STEINER et al., 2004: 52 y ss., y STEENBERGEN et al., 2003: 27 y ss.). Es probable, sin embargo, que este tipo de apreciaciones no pueda desvincularse del examen de la calidad del debate parlamentario en su conjunto ${ }^{26}$. Por otra parte, sería preciso completar este esquema con criterios relativos al contenido: determinar si la argumentación sobre eficacia es mejor o peor, más allá de su calidad formal, exige articular criterios específicos, que podrían derivarse de las teorías de la evaluación legislativa. Se trataría, en suma, de integrar las diversas dimensiones del debate en un modelo analítico que permita establecer su corrección formal, material y pragmática (vid. ATIENZA, 2005). No obstante, eso corresponde ya a una teoría general de la argumentación legislativa que aún está por desarrollar, y supera con mucho el propósito de este trabajo. El planteamiento esbozado aquí, en cualquier caso, es suficiente para ensayar al menos un análisis «descriptivo», y mostrar un ejemplo de cuál pueda ser el alcance de la argumentación sobre eficacia en la justificación de las leyes.

\section{LOS ARGUMENTOS DE EFICACIA EN EL DEBATE SOBRE EL MATRIMONIO HOMOSEXUAL}

Trataré a continuación de ejemplificar los dos primeros apartados de este esquema con los debates parlamentarios acerca de la llamada ley del matrimonio homosexual ${ }^{27}$. Pero antes de hacerlo conviene sintetizar la confrontación interpretativa a propósito del art. $32 \mathrm{CE}$, ya que delimita el marco en el que tiene lugar la argumentación sobre eficacia.

\subsection{El art. $32 \mathrm{CE}$ y las razones del matrimonio homosexual: tácticas interpretativas}

La reforma legal consiste básicamente en agregar un párrafo al art. 44 del Código Civil, con el siguiente tenor: «el matrimonio tendrá los mismos requisitos y efectos cuando ambos contrayentes sean del mismo o de diferente sexo». La exagerada controversia que suscitó tan escueto párrafo se explica fácilmente: el matrimonio suele ser considerado — sobre todo si se vincula a la familia - una institución capital cuya regulación afecta de plano al núcleo normativo de la sociedad. De ahí que la discusión sobre la reforma se planteara en seguida en términos de constitucionalidad y que el art. $32 \mathrm{CE}$, especialmente su primer apartado («el hombre y la mujer tienen derecho a contraer matrimonio con plena igualdad jurídica»), fuera la norma de referencia tan-

${ }^{26}$ Convendría asimismo tener en cuenta otros factores, como las percepciones sobre la calidad del debate que expresan los propios parlamentarios o la invocación de las reglas de debate fijadas en los reglamentos de las cámaras -en el caso español, por ejemplo, el art. 71 del Reglamento del Congreso.

${ }^{27}$ Ley 13/2005, de 1 de julio, por la que se modifica el Código Civil en materia de derecho a contraer matrimonio. Se analizaron tres debates en el Congreso (Pleno: 17 de marzo, 21 de abril y 30 de junio de 2005) y dos en el Senado (Comisión de Justicia, 14 de junio de 2005; Pleno, 22 de junio de 2005). Dado que en esta ley no se plantean cuestiones de estrategia regulativa en el sentido de WITTEVEEN, omitiré el tercer apartado del esquema. 
to para detractores como para partidarios del proyecto ${ }^{28}$. Unos y otros recurren, a menudo de forma explícita, a todos los cánones de interpretación habituales en derecho, desde el literal y el sistemático hasta el histórico y el de adecuación social. Sus tácticas argumentativas, no obstante, son distintas: mientras que la oposición sustenta el reproche de inconstitucionalidad en una interpretación centrada en el art. $32 \mathrm{CE}$ - aunque tiende a conectarlo con la protección a la familia y la infancia (art. $39 \mathrm{CE}$ ) - , la defensa procura abrir el enfoque interpretativo al principio de igualdad y no discriminación para sostener que la ley no sólo es constitucionalmente posible, sino incluso necesaria.

La tesis constitucional decisiva, en contra de la reforma, afirma que el art. $32 \mathrm{CE}$ fija una garantía institucional del matrimonio (heterosexual), con lo que sus perfiles definitorios no pueden alterarse por vía legislativa: la redefinición del matrimonio caería entonces fuera del margen de libre configuración del legislador ${ }^{29}$. Para enervar esta tesis se aduce que la heterosexualidad de la pareja no forma parte de esa garantía institucional y, por tanto, que ampliar la extensión del concepto de matrimonio no quiebra la dimensión objetiva del art. 32 CE. Y así, se insiste una y otra vez en que no se producirá ningún perjuicio a las parejas heterosexuales ya casadas, ni a las que quieran casarse, y en que la ley no menoscaba los derechos de nadie, sino que se limita a extender los beneficios de la institución a un cierto colectivo de personas ${ }^{30}$. A los valedores del proyecto, con todo, les conviene interpretar el artículo, no ya en términos de garantía institucional, sino como el reconocimiento de un derecho subjetivo. Lo que el legislador no podría hacer, con esta interpretación, es suprimir el matrimonio, si bien nada impediría su ampliación a las parejas del mismo sexo ${ }^{31}$.

Hasta aquí, el tema discutido es si la reforma vulnera o no la constitución, o sea, si es posible. Pero sus partidarios dan todavía un paso más y la presentan como el cumplimiento de un mandato constitucional, que tratan de construir interpretativamente integrando el art. $32 \mathrm{CE}$ con el principio de igualdad y no discriminación (art. $14 \mathrm{CE}$ ), así como con el deber del legislador de promover condiciones efectivas de libertad e igualdad (art. 9.2 CE) y de asegurar la dignidad y el libre desarrollo de las personas

${ }^{28}$ Sobre la interpretación del art. 32 CE, en defensa del proyecto, López Aguilar (DS Congreso 17 de marzo de 2005, p. 3771), García Suárez (DS Congreso 17 de marzo de 2005, p. 3782a), Uría (DS Congreso 17 de marzo de 2005, p. 3784a y 30 de junio de 2005, p. 5222b), Cerdá (DS Congreso 17 de marzo de 2005, p. 3786a), Montón (DS Congreso 21 de abril de 2005, p. 4120a), Villarrubia (DS Congreso 17 de marzo de 2005, p. 3787b), Díaz Tejera (DS Senado 22 de junio de 2005, pp. 2503b, 2509a, 2510b), y Etxegoyen (DS Senado 22 de junio de 2005, pp. 2515-2516); contra, Torme (DS Congreso 17 de marzo de 2005, p. 3777 a, y 21 de abril de 2005, p. 4118b), Vindel (DS Senado 14 de junio de 2005, p. 3b; 22 de junio de 2005, pp. 2506, 2510a) o Conde (DS Senado 14 de junio de 2005, p. 11a). Para el debate doctrinal sobre la reforma vid., por ejemplo, L. M. DíEZ-Picazo, 2007; Gavidia, 2007; VALieres, 2007; DomíngueZ, 2006; Cerdeira, 2005, o AMUNÁTEGUI, 2005.

${ }^{29}$ Vid., en particular, Torme (DS Congreso 17 de marzo de 2005, pp. 3776b-3777a), Vindel (DS Senado 22 de junio de 2005, p. 2506b) o Casas (DS Senado 22 de junio de 2005, p. 2501a), quienes aluden a su vez al dictamen del Consejo de Estado. Frente a la tesis de la garantía institucional vid., por todos, Díaz Tejera (DS Senado 22 de junio de 2005, p. 2503a-b).

${ }^{30}$ Esta tesis aparece recurrentemente: vid., por ejemplo, López Aguilar (DS Congreso 17 de marzo de 2005, p. 3772a) o Pigem (DS Congreso 21 de abril de 2005, p. 4115b).

${ }_{31}$ Véase, por todos, Etxegoyen (DS Senado 22 de junio de 2005, pp. 2515b-2516a), quien tras insistir en la regulación diferenciada de la protección a la familia (art. 39 CE) y del matrimonio, sostiene que: «el derecho a contraer matrimonio no es un derecho fundamental sino [...] un derecho subjetivo a suscribir el pacto que necesariamente comporta el matrimonio». 
(art. 10.1 CE) ${ }^{32}$. La forma de plantear el problema ya condiciona la respuesta, así que llevar el debate a términos de igualdad y no discriminación era la táctica clave, ya que invertía la carga justificatoria: son los detractores del proyecto quienes han de fundamentar que la diferencia de tratamiento jurídico debe mantenerse ${ }^{33}$. Pero desde el momento en que se admite - y esto al menos es lo que todos declaran — que la orientación sexual de una persona es irrelevante para los derechos y obligaciones, y que un homosexual no es mejor ni peor que un heterosexual, resulta difícil justificar convincentemente que uno pueda casarse, o adoptar y educar a un niño, y otro no ${ }^{34}$.

\subsection{Identificación de argumentos relativos a la eficacia}

Que se trate de una ley de corte ético-moral no implica que las cuestiones de eficacia sean desatendidas: en los debates que precedieron a su aprobación encontramos argumentos de eficacia en casi todas sus variantes. Aunque la eficacia de cumplimiento queda fuera de consideración - la ley no contiene normas de mandato- en los debates sí se tematiza la obligación de los jueces y funcionarios de aplicarla, y al menos en un sentido oblicuo cabría decir que se aborda la eficacia de aplicación. A este respecto, la cuestión — que aquí interesa en tanto que cuestión fáctica- es si las autoridades celebrarán o no matrimonios entre parejas del mismo sexo y los inscribirán en el registro civil ${ }^{35}$. El siguiente esquema intenta reconstruir la argumentación sobre este punto:

32 «Hay base bastante en la propia Constitución cuando se habla de igualdad en el art. 14, o de la obligación de los poderes públicos de levantar los obstáculos que dificulten el efectivo disfrute de los derechos [...], o en el art. 10 cuando se alude a la dignidad de la persona y al libre ejercicio de la personalidad», y no importa «que en la mente del constituyente [...] no estuviese esta posibilidad de igualar», porque el texto debe «ir adecuándose a las circunstancias del tiempo, conforme a lo que dice el art. 3 del Código Civil» (Uría, DS Congreso, p. 5222b); así también, López Aguilar (DS Congreso 17 de marzo de 2005, p. 3769b ss.), Uría (DS Congreso 17 de marzo de 2005, p. 3784a), Díaz Tejera (DS Senado 22 de junio de 2005, p. 2503 a-b) o Etxegoyen (DS Senado 22 de junio de 2005, p. 2503b: para esta última se trata de que «el art. 14 ilumine la literalidad del art. 32»; contra, TORME (DS Congreso 17 de marzo de 2005, p. 3777a): «no existe ese mandato constitucional del que usted ha hablado» —esta réplica se basa sólo en la tesis de la garantía institucional.

33 «Sinceramente creo que no tenemos que justificarnos. [...] Está aceptada la idoneidad de las personas homosexuales para adoptar y educar niños tanto social como científica y jurídicamente. Quien defienda lo contrario es quien debe justificar que sus argumentos» no se basan «en el hecho de discriminar por razones de orientación sexual» (Montón, DS Congreso 21 de abril de 2005, p. 4120b). Vid., sobre este punto, en relación con el debate en Estados Unidos y Holanda, VAN DER BURG (2005: 258 y 269).

34 Ejemplarmente, a propósito de la adopción: «no entiendo muy bien cómo se puede estar convencido de que la homosexualidad no es una patología, que no es en sí una cosa mala ni buena [...], que los homosexuales son unos seres humanos más [...], exactamente igual que los heterosexuales, y, posteriormente, decir que pueden representar un problema o que pueden ser dañinos para los niños que convivan en su entorno familiar» (Bofill, DS Senado 22 de junio de 2005, p. 2518a).

35 En los debates aparecen otros dos temas asociados con la eficacia de aplicación. En el Congreso, el GP Mixto propuso una disposición final (enmienda n. ${ }^{\circ} 5$ ) para neutralizar la tendencia de las instituciones, «empezando por la administración de justicia», a buscar «cualquier vericueto» legal para «actuar en casos puntuales de una forma no equitativa» (Rodríguez Sánchez, DS 21 de abril de 2005, p. 4111a). Y el GP Popular en el Senado planteó una vacatio legis de seis meses para que las administraciones pudieran afrontar el cambio. 


\section{FIGURA 2 \\ Argumentación sobre eficacia de aplicación}

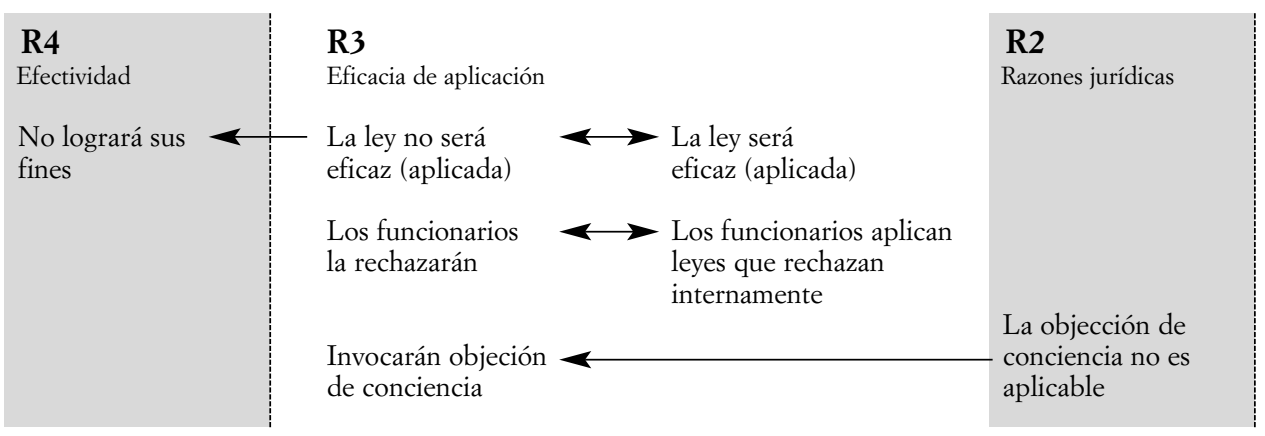

El proyecto no preveía una causa de abstención por razones de conciencia ni una disposición que asegurase el matrimonio ante la posible negativa de alcaldes o concejales a celebrarlo. Sus detractores aducen que la ley presentará problemas de aplicación: muchos jueces o funcionarios la rechazarán, por lo que no será eficaz y tampoco logrará sus fines. Y para desvirtuar la réplica de que los funcionarios aplican también normas con las que no están de acuerdo ${ }^{36}$, se insiste en que no será un mero rechazo interno: los funcionarios se acogerán a la objeción de conciencia para inaplicar la ley, ya que viola sus convicciones profundas ${ }^{37}$. El gobierno estima que esto no ocurrirá, porque esa figura no es aplicable aquí. Con ello acaban las predicciones de eficacia y la discusión pasa al plano jurídico-constitucional, donde se analizan el sentido y los límites de la objeción de conciencia ${ }^{38}$.

Los parlamentarios plantean asimismo un tema ligado a la eficacia como movilización: cuántas personas usarán la norma o podrían llegar a usarla.

Las estimaciones del número de usuarios potenciales se contradicen (Figura 3). La oposición considera que se está legislando para una minoría insignificante, lo que haría innecesaria la medida ${ }^{39}$. Sus defensores replican que no hay datos fiables al respec-

36 «Yo he aplicado en mi vida profesional leyes que no me gustaban»; «había jurado cumplir la ley, y aunque no me gustara la he tenido que cumplir, acatar y aplicar» (Granado, DS Senado 14 de junio de 2005, p. 13b). En calidad de alcalde, un diputado contrario a la ley admite que «va a celebrar matrimonios entre personas del mismo sexo [...] con absoluta lealtad y sometimiento a la ley» (Guinart, DS Congreso 21 de abril de 2005, p. 4116b).

${ }^{37}$ Habrá «problemas de choque entre la norma y las conciencias individuales», y el gobierno tiene miedo «a que esta ley no tenga virtualidad práctica si se introduce la libertad de conciencia» (Vindel, DS Senado 14 de junio de 2005, p. 4a, y 22 de junio de 2005, p. 2507a); «ya veremos que pasará cuando algún ayuntamiento se niegue a celebrar el matrimonio, ya veremos el camino del contencioso administrativo, ya veremos la indiferencia o la imposibilidad de celebrarlo» (Badía, DS Senado 22 de junio de 2005, p. 2514a).

${ }^{38}$ Véase, en especial, las intervenciones de Díaz Tejera (DS Senado 14 de junio de 2005, pp. 5b, 15a-b; 22 de junio de 2005, pp. 2509a y 2520a), Conde (DS Senado 14 de junio de 2005, p. 10b, 11a, 14a-b, 16a), Granado (DS Senado 14 de junio de 2005, p. 13b), Bonás (DS Congreso 30 de junio de 2005, p. 5224a-b) y Vindel (DS Senado 22 de junio de 2005, pp. 2507a-b, 2510a).

${ }^{39}$ Hay unos «nueve millones de matrimonios [...], frente a unas diez mil parejas estables homosexuales, según [...] datos del censo. Es una desproporción numérica de tal calibre, que no justifica en modo alguno la necesidad social de la figura» (Conde, DS Senado 14 de junio de 2005, p. 12a); «se está legislando para una gran 


\section{FIGURA 3 \\ Argumentación sobre eficacia de movilización}

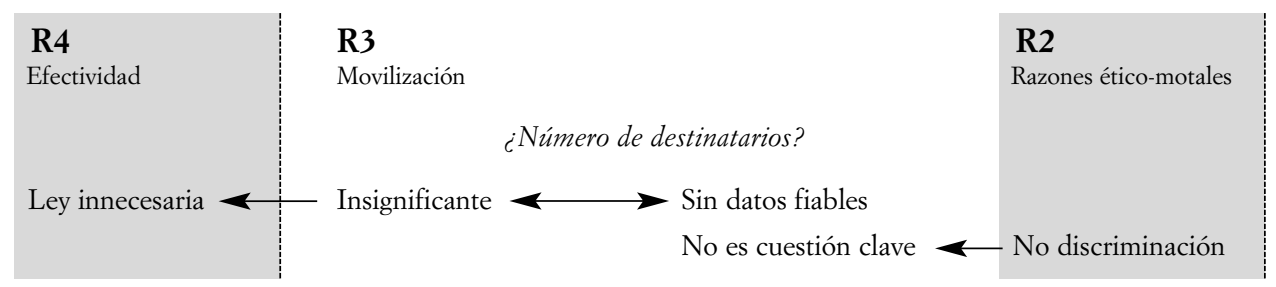

to, pero que ello, en todo caso, no es esencial, ya que el objetivo moral de erradicar la discriminación no puede hacerse depender de números o porcentajes; sería más importante, en este sentido, que la ley resulte aceptable para sus destinatarios ${ }^{40}$.

La mayor parte de los argumentos esgrimidos en los debates aluden a la racionalidad instrumental y al impacto y efectos sociales de la medida legislativa, es decir, operan en el orden de la efectividad. Se trata de una discusión muy compleja en términos de estructura y contenido, pero creo que podría esquematizarse así:

\section{FIGURA 4 \\ Argumentación sobre efectividad}

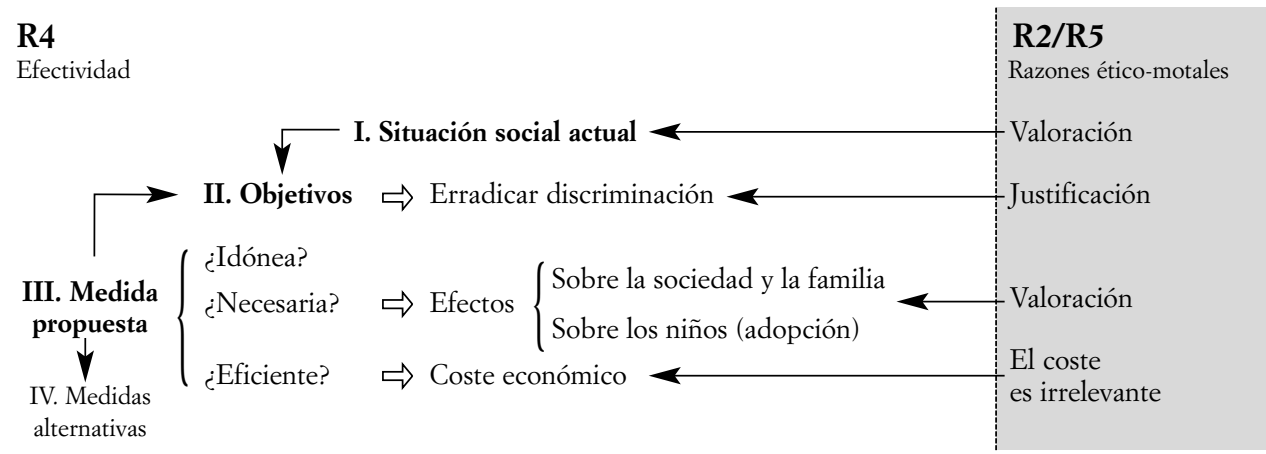

minoría, que según el INE supone un 1 por 100 de la población» (Vindel, DS Senado 22 de junio de 2005, p. 2521a).

${ }^{40}$ Como la ley «no va contra nadie, va a favor de reconocer derechos, [...] lo de menos es el número, porque eso también es objeto de debate»; uno de los «presuntos expertos» que comparecieron insistía en que «no llega ni al 1 por $100 » ;$ otro, que «era un 10 por 100 o un 15 por 100. ¿Es que acaso la nobleza y la justicia de una causa está en función del número? [...] Nada tiene que ver que sea un 1 por 100, un 10 por 100 o un 15 por 100 , entre otras cosas, porque sinceramente no hay registros» (Díaz Tejera, DS Senado 22 de junio de 2005, p. 2504a); hay que «hacer un documento definitivo que sea plenamente aceptable al menos por aquellos a los que va dirigido, que son los que tratan de utilizar una fórmula del matrimonio nueva» (Mardones, DS Congreso 17 de marzo de 2005, 3781a). Los opositores niegan esto último: «este proyecto ni siquiera representa el sentir del conjunto de las personas homosexuales» (Torme, DS Congreso 17 de marzo de 2005, p. 3778a). 
Puede decirse que comienza con la descripción (y valoración) de la situación social actual [I]. Abundan aquí las alusiones a la evolución de la sociedad en los últimos tiempos, en relación con unos modelos de familia y de pareja cada vez más plurales, así como con la mejor percepción social y la creciente visibilidad de los homosexuales ${ }^{41}$. A grandes rasgos, todos vienen a coincidir en la descripción de la realidad social, y también la valoran (aportando razones morales y constitucionales) como discriminatoria, cuando menos en el sentido de ser necesaria alguna acción legislativa para corregirla ${ }^{42}$. A los partidarios del proyecto les interesa resaltar, además, que existe una fuerte demanda social de un cambio jurídico en la materia ${ }^{43}$, así como el hecho de que una persona soltera, sin importar su orientación sexual, tiene ya la posibilidad de adoptar, y que este tipo de adopciones no son infrecuentes ${ }^{44}$.

En vista de esa situación se abordan los fines u objetivos [II]. La ley no pretendería sino «elevar a legal lo que es real» ${ }^{45}$. La vaguedad de la fórmula evita la controversia, y sucede lo mismo con el objetivo que explícitamente declara perseguir el proyecto: eliminar la discriminación que sufren los homosexuales en cuanto a desarrollo afectivo y familiar. La justificación de los fines obedece a razones morales y constitucionales que todos comparten, pero, en el plano de la efectividad, lo que se discute es el medio elegido para alcanzarlos: introducir un cambio jurídico que amplía el derecho a contraer matrimonio recogido en el art. $32 \mathrm{CE}$ a personas del mismo sexo [III] ${ }^{46}$. Frente a ello

${ }^{41}$ «El modelo familiar evoluciona en todo el mundo. En Europa, las familias monoparentales de madres con hijas han aumentado un 7 por 100»; «las parejas sin hijos, un 19 por 100; los hogares unipersonales, un 11 por 100; las parejas de hecho, entre el 10 por 100 y el 25 por 100», según Eurostat (Bonás, DS Congreso 30 de junio de 2005, p. 5223b); el cambio de percepción social es «enorme: [...] en 1975, el 83 por 100 [...] consideraba que la homosexualidad debía ser extirpada de la sociedad. En 1997, según una encuesta del CIS, un 57 por 100 aceptaba el matrimonio homosexual»; la homosexualidad es «practicada con mayor o menor frecuencia por más del 30 por 100 de las personas» (Navarro, DS Senado 21 de abril de 2005, p. 4111b); las familias homoparentales son «un hecho social indiscutible», no «una realidad nueva que esta ley» esté inventando (Bofill, DS Senado 22 de junio de 2005, p. 2517b); «hoy tenemos tantas tipologías de familias como personas y núcleos familiares» (García Suárez, DS Congreso 17 de marzo de 2005, p. 3782b); «es cierto que en los últimos años han aparecido junto al matrimonio otras formas de convivencia que demandan una regulación» (Vindel, DS Senado 22 de junio de 2005, p. 2505b).

${ }_{42}$ «El profundo cambio que ha experimentado la sociedad [...] no puede sino llevarnos al reconocimiento social [...] y obligadamente, al reconocimiento jurídico de dicha realidad» (Etxegoyen, DS Senado 22 de junio de 2005, 2515b); «las cosas están cambiando socialmente y también debemos cambiarlas legalmente» (Cerdá, DS Congreso 17 de marzo de 2005, p. 3786a). También para los detractores de la ley, «la sociedad española ha evolucionado [...], y éste era el momento [...] de reconocer legislativamente lo que la sociedad española admite con normalidad en su convivencia» (Torme, DS Congreso 21 de abril de 2005, p. 4117a).

${ }_{43}$ «Estamos seguros de que [...] la mayor parte de la ciudadanía comprende, respalda, entiende y participa de esta decisión» (Rodríguez, DS Congreso 30 de junio de 2005, p. 5220b). Contra: no hay «una demanda social ni un clamor popular» (Casas, DS Senado 22 de junio de 2005, 2502a); según «la encuesta del CIS de junio del año pasado», no hay «necesidad social de buscar nuevas formas de adopción» (Vindel, DS Senado 22 de junio de 2005, p. 2507a).

${ }^{44}$ Un «homosexual puede concurrir a un procedimiento de adopción, y la evidencia empírica» prueba que lo hacen (López Aguilar, DS Congreso 17 de marzo de 2005, p. 3770b); así también, Bofill (DS Senado 14 de junio de 2005, p. 7b) o Villarubia (DS Congreso 17 de marzo de 2005, p. 3788a); contra, Casas (DS Senado 22 de junio de 2005, p. 2501b).

${ }^{45}$ Esta expresión fue muy repetida; véase, por ejemplo, López Aguilar (17 de marzo de 2005, p. 3770a), Mardones (17 de marzo de 2005, p. 3770a), Díaz Tejera (14 de junio de 2005, p. 4b-5a; 22 de junio de 2005, pp. 2502b y 2509b) o Ayala (14 de junio de 2005, p. 6b).

${ }_{46}$ «El Partido Popular comparte plenamente el objetivo de esta ley, pero no el camino elegido» (Vindel, DS Senado 14 de junio de 2005, p. 3a); el Grupo «Popular está plenamente de acuerdo con» el objetivo de remover toda discriminación fundada en la orientación sexual»; «en lo que no estamos en absoluto de acuerdo es en la fórmula que ha elegido el Gobierno» (Vindel, DS Senado 22 de junio de 2005, p. 2505b). 
se elevan dos objeciones básicas: de un lado, que la ley no acabará con la discriminación (no es idónea) ${ }^{47}$; de otro, que resulta demasiado polémica y provocará efectos sociales negativos que pueden evitarse con medios alternativos (no es necesaria) ${ }^{48}$. El grueso de la confrontación atañe a este último aspecto.

El impacto y los efectos de la ley se discuten respecto de la sociedad en su conjunto, respecto del matrimonio heterosexual y respecto de los niños adoptados; y, más aún que en la interpretación de la realidad social actual, los parlamentarios intercalan aquí dos modos de argumentación, el empírico (se producirá o no un determinado efecto) y el normativo (se valora un efecto como positivo o negativo). En el plano más general, la crispación política ya generada y la quiebra de la estructura social a que conduciría el proyecto - al socavar pilares institucionales como la familia y el matrimonio- son las bazas argumentativas de sus detractores; frente a quienes predicen la desintegración y la fractura de la sociedad ${ }^{49}$, se arguye que ésta será realmente más justa y menos dis-

47 «La opción que ustedes han elegido no es la idónea para el logro de los objetivos propuestos» (Torme, DS Congreso 17 de marzo de 2005, p. 3776b); «las discriminaciones que puedan darse en el tejido social no se evitan mediante la configuración legal de un matrimonio» que dé cabida a dos realidades diferentes (Durán i Lleida, DS Congreso 17 de marzo de 2005, p. 3774b; Casas, DS Senado 22 de junio de 2005, p. 2501b); «tengo dudas de que por el hecho de que se puedan casar entre sí» se vayan a solucionar problemas reales de discriminación: «¿por el simple hecho de estar casados [...] va a cesar esa discriminación?» (Vindel, DS Senado 22 de junio de 2005, p. 2521b). Defienden la idoneidad del proyecto, por ejemplo, Uría (DS Congreso 17 de marzo de 2005, p. 3785b); Navarro (DS Congreso 30 de junio de 2005, p. 5221a) o Montón (DS Congreso 21 de abril de 2005, p. 4120b).

48 «Nuestro grupo ha propuesto crear una figura jurídica específica, la unión civil estable que configura un marco de derechos y obligaciones para estas parejas sin que pueda haber discriminación alguna» (Torme, DS Congreso 17 de marzo de 2005, p. 3776b); «no deben desconocerse otras vías que permitan alcanzar los objetivos que se persiguen y en particular la regulación diferenciada de la nueva forma de convivencia en pareja»; «no es indispensable para el logro de los objetivos que se persiguen» (Torme, DS Congreso 17 de marzo de 2005, p. 3777a); «para conseguir los mismos fines de reconocimiento, igualdad y efectos jurídicos, podía haberse recurrido a otras figuras [...] perfectamente asumibles por todos» (Guinart, DS Congreso 21 de abril de 2005, p. 4116b); «han actuado como si la única alternativa» para acabar con la discriminación fuera ésta, pero «saben que no es verdad, [...] que hay otras alternativas pacíficas, centradas, y que tienen un amplio apoyo social y político»; «la evolución de la sociedad española permite con relativa facilidad aprobar esa figura jurídica específica [unión civil estable] que soluciona el problema sin crear otros y que contaría con un amplísimo respaldo social y político» (Torme, 21 de abril de 2005, pp. 4117b y 4119a); «un modelo distinto de convivencia en pareja demanda un distinto tratamiento jurídico, sin forzar la aplicación de normas previstas para un modelo diferente con los problemas que ello puede acarrear»; «el reconocimiento legal y la atribución de efectos jurídicos a las uniones de personas del mismo sexo no requiere la desnaturalización de la institución matrimonial. Se podría haber regulado perfectamente de otra manera» (Casas, DS Senado 14 de junio de 2005, p. 2b, y 22 de junio de 2005 , p. 2501b); «la iniciativa presentada [...] por el Partido Popular expresa en su preámbulo objetivos similares», pero es «mucho más elaborada y clarificadora [...], además de mucho más pacífica» (Vindel, 22 de junio de 2005, p. 2506a); para garantizar los derechos de los homosexuales «había caminos conocidos, seguros, pacíficos, que se podían recorrer desde la unidad y sin riesgos» (Torme, DS Congreso 30 de junio de 2005, p. 5225b). Contra: esta ley «resuelve de la manera más efectiva posible, sin medias tintas y recelos, la discriminación intolerable que sufrían cientos de ciudadanos y ciudadanas» (Bofill, DS Senado 22 de junio de 2005, 2517b).

49 «Es un error que [...] pagará toda la sociedad» (Durán i Lleida, DS Congreso 17 de marzo de 2005, p. 3775a); también así, Casas (DS Senado 22 de junio de 2005, p. 2502a). Esta iniciativa «provoca confrontación y crispación social», lleva «a la fractura social» (Torme, DS Congreso, 17 de marzo de 2005, p. 3777b, y 21 de abril de 2005, p. 4118b) y crea «fuerte división social, desoyendo la posición contraria de millones de ciudadanos [...] representados por otros partidos» y expresada «a través de asociaciones e instituciones importantes de nuestra sociedad» (Vindel, DS Senado 14 de junio de 2005, p. 9b, citando a una senadora de Entesa Catalana); «ningún gobierno que basara en la manipulación su opción política [...] ha triunfado jamás. Tengan por seguro que ustedes tampoco lo harán y que la sociedad española y las personas homosexuales no sólo conocen nuestra posición, sino que la respetan y coinciden más con ella que con la que hoy se aprobará»; «estoy segura [...] de que bajo ningún concepto esa será la posición dominante que entienda la gente» (Torme, DS Congreso 30 de junio de 2005, p. 5225a). 
criminatoria; y, ante el argumento de la reacción social adversa — detectable ya mientras tienen lugar los debates-, el gobierno alega que cuenta con el respaldo electoral de los ciudadanos ${ }^{50}$. Esta discusión se entrevera con la de los efectos sobre la propia institución matrimonial: para unos, la ley implica desvirtuarla y hacerla irreconocible - esto enlaza con la interpretación jurídica del art. 32 CE que restringe la institución a la pareja heterosexual—, mientras que para otros no causará daño alguno al matrimonio convencional ${ }^{51}$.

La polémica más enconada se plantea en cuanto a la adopción por parte de parejas homosexuales y a los efectos que ésta puede acarrear para los adoptados, en particular a su impacto psicológico y su repercusión sobre los vínculos afectivos y las relaciones sociales de los niños. Los detractores del proyecto sugieren serios perjuicios para el desarrollo de la personalidad, pero no aportan argumentos empíricos específicos. Se centran más bien en la configuración jurídico-constitucional de la adopción y en equiparar la filiación adoptiva con la biológica ${ }^{52}$, y sólo destacan efectos negativos conexos, como la imposibilidad de adopción internacional ${ }^{53}$, o hipotéticos, como el daño irreparable que sufrirían los niños adoptados si la ley termina declarándose inconstituciona ${ }^{54}$. El otro bando replica que la homosexualidad de los adoptantes es de todo punto irrelevante para el adecuado desarrollo infantil, y que hasta podría traer aparejadas consecuencias positivas, como actitudes de mayor tolerancia ${ }^{55}$; la ley aseguraría

${ }^{50}$ «Me gustaría saber que pasa con el talante del Gobierno ante las más de medio millón de firmas que han promovido una iniciativa legislativa» para «remarcar el carácter heterosexual del matrimonio» e «impedir la adopción de parejas homosexuales» $\mathrm{y}$ «frente a cuatro religiones [...] pidiéndole con una única voz que retire este proyecto» (Vindel, DS Senado 14 de junio de 2005, p. 3b). Para el gobierno, la ley estaba en el programa electoral, luego «tuvo el refrende de cerca de doce millones de votos» (Díaz Tejera, DS Senado 14 de junio de 2005, p. 4b); la réplica es que, aun asumiendo que «doce millones de votantes [...] compartieran este punto en concreto, no dejaría de ser cierto que faltan treinta y dos millones de españoles» (Conde, DS Senado 14 de junio de 2005, p. 11b).

${ }^{51}$ La nueva ley implica «debilitar la institución más importante de la sociedad. No parece que convenga a la sociedad en su conjunto que se debiliten instituciones [...] que son su propio cimiento» (Vindel, DS Senado 14 de junio de 2005, p. 9a) o se alteren «los perfiles propios» de la institución (Casas, DS Senado 22 de junio de 2005, p. 2501a). A favor de la ley se aduce que «no viene a minorar el matrimonio heterosexual» (López Aguilar, DS Congreso 17 de marzo de 2005, p. 3770a); lejos de corromper la institución, «la defiende y enriquece porque no obliga a nadie y no va en contra del matrimonio heterosexual» (Etxegoyen, DS Senado 14 de junio de 2005, p. 7b); «¿cómo puede [...] un simple registro en el juzgado destruir las familias tradicionales?» (Ayala, DS Senado 22 de junio de 2005, p. 2513a).

52 « ¿Están ustedes seguros de que no se va a condicionar el libre desarrollo de la personalidad de los niños adoptados por parejas homosexuales?» (Torme, DS Congreso 17 de marzo de 2005, p. 3778a). Argumentos jurídicos sobre la adopción aducen, por ejemplo, Durán i Lleida (DS Congreso 17 de marzo de 2005, p. 3774b), Casas (DS Senado 22 de junio de 2005, p. 2501b) o Vindel (DS Senado 14 de junio de 2005, p. 4a, y 22 de junio de 2005, p. 2506a).

53 «El 90 por 100 de las adopciones que se realizan vienen de diez Estados que [...] expresamente prohíben que se pueda adoptar por parejas homosexuales; [...] España puede convertirse en un país poco fiable desde el punto de vista de la adopción internacional» (Torme, DS Congreso 17 de marzo de 2005, p. 3778a); así también, por ejemplo, Vindel (DS Senado 22 de junio de 2005, p. 2522a) o Guinart (DS Congreso 21 de abril de 2005, p. 4116b), quien aduce además que este problema «puede distorsionar las listas de espera para la adopción nacional».

${ }_{54}$ Así, por ejemplo, Vindel (DS Senado 22 de junio de 2005, p. 2507a).

${ }_{55}$ Según el Consejo de Europa, se han hecho en los últimos años «multitud de estudios en este sentido [...]. Ninguno ha podido determinar que el hecho de ser educado por padres homosexuales perjudica a esos niños, ni que los padres homosexuales sean peores padres que los padres heterosexuales, ni que estos niños se vean expuestos, a su vez, a ser homosexuales. Es más, todos los estudios empíricos insisten en el mismo dato, en que no es una variable» significativa o relevante de cara a la idoneidad del adoptante. El «estudio empírico 
además el reconocimiento de los hijos que ya viven en el seno de familias homoparentales $^{56}$.

En la discusión sobre los efectos empíricos predominan dos recursos argumentativos. A favor de la ley encontramos, por una parte, argumentos comparativos referidos tanto a su impacto en otros países como al de medidas igualmente polémicas aprobadas en legislaturas anteriores. Se aduce, así, que de otras experiencias similares en el Derecho comparado (Ontario, Bélgica, Holanda) no se han derivado consecuencias sociales desintegradoras ni perjuicios para los adoptados por parejas homoparentales ${ }^{57} ; \mathrm{y}$ se insiste recurrentemente en que los mismos tipos de argumentos —en su mayoría, falacias de pendiente resbaladiza- fueron vertidos antes en contra de la separación y el divorcio, la despenalización del aborto o la investigación con células madre, sin que se hayan verificado los efectos catastróficos que en su día se atribuyeron a las respectivas leyes ${ }^{58}$. Por otra parte, y en relación con el problema de la adopción, se invocan las eva-

encargado por el Defensor del Menor [...] al Colegio de Psicólogos de Madrid y a la Universidad de Sevilla» insistía en que, «en términos de autoestima, de integración social y de prestigio en el barrio, después de haber evaluado a los profesores, a los tutores, a los padres», «el proceso de aprendizaje y de integración era idéntico y que, si había algún factor distinto, era una especial tolerancia a la diversidad, a la aceptación de la homosexualidad e, incluso, una mayor flexibilidad respecto a los roles de género» (Díaz Tejera, DS Senado 22 de junio de 2005, p. 2519b); insiste en ello, por ejemplo, Bofill (DS Senado 22 de junio de 2005, p. 2518a-b); «el único estudio empírico que hay afirma que no fueron mejores ni peores» otros niños o niñas: «presentaron igualdad en el proceso de aprendizaje, en el proceso de integración socioafectiva, o en el de madurez relacional» (Díaz Tejera, DS Senado 14 de junio de 2005, pp. 4b-5a); «en España, en el año 1987 había niños y niñas así educados, que hoy [...] tienen 20 ó 30 años, y en la práctica se ha demostrado que han tenido un desarrollo social y educativo absolutamente idéntico al resto» (Díaz Tejera, DS Senado 22 de junio de 2005, p. 2505b); «contrastemos con la realidad esa especie de psicología o pedagogía preventiva», y «no con las creencias o preferencias. ¿Qué dicen todos los estudios de la Asociación norteamericana de psicología? [...] O la Asociación de psiquiatría [...] Dicen claramente que es un rasgo no relevante para la prueba de idoneidad»; «ningún dato empírico [...] cuestiona la idoneidad de un ser humano» homosexual para adoptar; «un ser humano o dos seres humanos siempre será mejor que un hospicio o una calle»; una persona homosexual puede ya adoptar si es idónea, y «no ha habido ni un solo caso en el que se haya impugnado una adopción unipersonal a alguien cuya fórmula de pareja» sea homosexual; «lo propio sería que no cuestionásemos ad futurum algo que en la realidad no existe» (Díaz Tejera, DS Senado 22 de junio de 2005, pp. 2508b y 2509a-b); «ustedes dicen que los homosexuales tienen menos capacidad para educar a sus hijos» y utilizan «como parámetro de capacidad para medir la educación de los hijos la orientación sexual, algo tan absurdo como decir que todos los gays son más simpáticos» (Navarro, DS Congreso 30 de junio de 2005, 5221b); cfr. López Aguilar (DS Congreso 17 de marzo de 2005, p. 3770b), Rodríguez Sánchez (DS Congreso 17 de marzo de 2005, p. 3779b); Villarubia (DS Congreso 17 de marzo de 2005, p. 3788a-b), Uría (DS Congreso 21 de abril de 2005, p. 4113a); Montón (DS Congreso 21 de abril de 2005, p. 4120b), Díaz Tejera (DS Senado 22 de junio de 2005, 2504b).

${ }_{56}$ Por ejemplo, Campuzano (DS Congreso 17 de marzo de 2005, p. 3775b) o Pigem (DS Congreso, 21 de abril de 2005, p. 4116a); y sobre los niños en espera de adopción: los «beneficiarios de la ley serán los gays y lesbianas, pero también los niños, que podrán contar con más protección» (Cerdá, DS Congreso 21 de abril de 2005 , p. 4114b); dicen que no es bueno «que estos niños tengan dos padres o dos madres», cuando «están recluidos en un centro de acogida»: «¿es mejor que no tengan nada o que tengan dos padres o dos madres?» (Ayala, DS Senado 14 de junio de 2005, p. 6b).

${ }_{77}$ Así, López Aguilar (DS Congreso 17 de marzo de 2005, p. 3772b); $c f r$. Díaz Tejera (DS Senado 22 de junio de 2005, p. 2503b).

${ }^{58}$ El matrimonio civil, la separación o el divorcio generaron «escándalo, y hoy son tantas las personas que se casan por lo civil y [...] se separan o divorcian con entera naturalidad» (Díaz Tejera, DS Senado 14 de junio de 2005, p. 5a); con el matrimonio civil parecía «que el cielo se iba a desplomar» y que se legalizaba «el concubinato y el amancebamiento»; «expresiones similares se plantearon [...] cuando se introdujeron la separación y el divorcio, con la despenalización de los anticonceptivos», con el aborto, «con las técnicas de reproducción asistida, con la investigación sobre células madre» (Díaz Tejera, DS Senado 22 de junio de 2005, pp. 2502b y 2503a); «estoy convencida de que a muchos senadores y senadoras que están felizmente divorciados les parece insólito pensar que su matrimonio no pudiera disolverse. [...] Con este asunto va a pasar lo mismo» y «no van 
luaciones de expertos (sociólogos y psicólogos), bien provengan de comparecencias previas en el parlamento - algunas muy sonadas - ${ }^{59}$, o de informes elaborados por diversos organismos. Parlamentarios de ambos signos se acusan mutuamente de descontextualizar o tergiversar las evaluaciones, pero tienden a admitir que no es fácil hacer estimaciones, que no hay datos suficientes para pronunciarse o que el discurso científico también está marcado por conflictos axiológicos ${ }^{60}$. Según la oposición, los escasos precedentes internacionales, las posibles repercusiones negativas y la ausencia de datos empíricos concluyentes, aconsejan, en un ejercicio de prudencia legislativa ${ }^{61}$, elaborar una ley sustancialmente distinta. Y por esa vía se trae a examen, junto a la racionalidad instrumental del medio elegido, la de posibles medidas alternativas [IV]. Atendiendo al contenido esencial de la norma, las propuestas consideradas fueron dos: la denominación de «unión civil estable» (en vez de «matrimonio») y el recurso a figuras jurídicas como el acogimiento o la tutela (frente a la adopción). Para la oposición, ambas cuentan con un mayor respaldo social, son menos controvertidas y más efectivas que el proyecto presentado. El argumento central para rechazarlas es de idoneidad: según los partidarios de la ley, no harían sino mantener o profundizar la discriminación ${ }^{62}$.

a ser necesarios veinticuatro años» (López Aulestia, DS Senado 22 de junio de 2005, p. 2511a); «no querían el divorcio y ahora hacen uso de él; no quieren el matrimonio entre personas del mismo sexo y a buen seguro se casarán, serán testigos en las bodas» (Montón, DS Congreso 30 de junio de 2005, p. 5227b).

59 «Nos parece lamentable el incidente que se produjo [...] de la mano de una determinada formación política. Sabemos que no es el sentir de todos sus componentes [...] pero de su mano llegó al Congreso el supuesto informe, lo que para nosotros fue una parodia [...], una auténtica ofensa, cuando se refería el doctor Polaino a las perniciosas consecuencias en las relaciones de pareja y en la influencia sobre los hijos. [...] Nos pareció una burla» (Uría, DS Congreso 30 de junio de 2005, p. 5223a).

${ }^{60} \mathrm{La}$ «mención que hace de informes que puedan avalar su posición, o de países que ya tienen legislada la materia» recoge únicamente lo que interesa, y «se citan instituciones y organismos que se han manifestado en un sentido, cuando son muy numerosos los que se han manifestado» en el contrario (Uría, DS Congreso 17 de marzo de 2005, p. 3785b); «se limitan a remitir [...] a la Asociación americana de psicología y a incluir a modo de conclusión un párrafo de seis líneas. [...] En un nuevo ejemplo de manipulación, citan un único párrafo de seis líneas y omiten el párrafo siguiente del estudio de esa asociación, que plantea serias dudas [...]. Las cosas no están claras, señorías» (Torme, DS Congreso 30 de junio de 2005, p. 5225b); «no hay estudios concluyentes sobre los efectos para el desarrollo armónico de los niños en parejas del mismo sexo», sino «opiniones contradictorias de los expertos» (Vindel, DS Senado 14 de junio de 2005, p. 9b, citando a una senadora de Entesa Catalana); «de los diez expertos que han venido, sólo dos han cuestionado que no sea cuestión de creencias, precisamente dos que no han llevado a cabo ninguna investigación empírica»; en términos psíquicos, de aprendizaje, de autoconcepto, de autoestima, de prestigio en su núcleo «no hay ningún dato riguroso», sólo creencias (Díaz Tejera, DS Senado 22 de junio de 2005, p. 2504b).

${ }^{61}$ En cuanto «a la adopción, la prudencia aconseja que la aplicación a las uniones homosexuales derive de una voluntad expresa» del legislador, no «como un efecto colateral» (Vindel, DS Senado 22 de junio de 2005, p. 2506b); «les hemos pedido que sobre todo en esta cuestión actuaran con prudencia»; «al margen de toda la legislación comparada, una vez más lanzan a España a una aventura» (Torme, DS Congreso 30 de junio de 2005, p. 5225a-b). El margen de libertad del legislador y su soberanía democrática contrarrestarían la ausencia de precedentes internacionales: «si hay pocos precedentes y se pretende utilizar este argumento como valedor para la no modificación, ¿qué quieren ustedes que les diga? Creo que tenemos derecho a ponernos un poco chulos [...]. Invoco desde esta tribuna nuestra libertad y capacidad de decisión como miembros de esta Cámara [...], para avanzar como nos dé la gana» (Etxegoyen, DS Senado 22 de junio de 2005, p. 2517a); «lo prudente y lo sensato es [...] que el derecho, en la medida de lo posible, se acompase con la realidad social» (Díaz Tejera, DS Senado 14 de junio de 2005, p. 5b); cfr. Díaz Tejera (DS Senado 22 de junio de 2006, p. 2503b).

${ }_{62}$ Agravarían «la misma barrera de discriminación [...] contra la que esta ley quiere pronunciarse» (López Aguilar, DS Congreso 17 de marzo de 2005, p. 3771a); «una regulación diferenciada [...] es discriminación, lo miren como lo miren; [...] los gays y lesbianas son como usted y como yo [...]. Son y están en igualdad con todos, perteneciendo a [...] todas las familias, en todas las clases sociales, en todos los grupos políticos; [...] están para lo bueno y para lo malo, para pagar impuestos y recibir prestaciones» (García Suárez, DS Congreso 17 de marzo de 2005, p. 3781b); «una "copia" del matrimonio para homosexuales lo único que haría es mantener en 
Dentro de la argumentación sobre efectividad hallamos también referencias al tema de la eficiencia, en las dos acepciones señaladas al iniciar este trabajo. El coste de la ley resultó ser un punto particularmente polémico. En la práctica legislativa española, los proyectos de ley han de acompañarse «de los antecedentes necesarios para pronunciarse sobre ellos» (art. $88 \mathrm{CE}$ ). En esta ocasión no se presentó un informe económico, y la falta de estimación de costes fue subrayada como una carencia principal. Sin embargo, frente al argumento del coste, se invoca el carácter esencialmente moral de la ley y el principio constitucional de igualdad ${ }^{63}$. En la argumentación puede reconocerse asimismo la idea de eficiencia procedimental: se adujo, por una parte, que el debate sería superfluo, pues habría de repetirse ante otras iniciativas legislativas presentadas en paralelo (una iniciativa popular y las presentadas por otros grupos); y, por la otra, que la ley sería recurrida y habría que volver a debatirla ${ }^{64}$.

Por último, es posible identificar argumentos relativos a la eficacia simbólica. Una buena porción del debate tiene que ver precisamente con el término «matrimonio», y ahí radica, de hecho, el núcleo de la oposición al proyecto, tanto dentro como fuera del parlamento. Al pronto parece llamativo que una simple palabra motive una polémica a escala social, o que una mera diferencia semántica haya de ocupar a los representantes políticos. La contienda acerca del nomen iuris, no obstante, constituye un ejemplo de cómo a través de una lucha simbólica tratan de proyectarse socialmente determinados valores; de ello son conscientes los legisladores. En tanto que controversia axiológica, esta discusión se ubica en el plano de la justificación ético-moral. Pero el valor simbólico se considera también en términos de eficacia: a juicio de sus defensores, la ley contribuirá a medio plazo a la normalización y mejora de las actitudes sociales hacia los homosexuales ${ }^{65}$. Luego no sólo es idónea para erradicar una discriminación concreta, sino

un registro aparte, en una lista aparte, [...], aparte y marginados, a una serie de ciudadanos» (Bofill, DS Senado 22 de junio de 2005, p. 2518a); «el único modo de otorgar plena igualdad» es el matrimonio (Navarro, DS Congreso 30 de junio de 2005, p. 5221a); vid. también Villarubia (DS Congreso 17 de marzo de 2005, p. 3787a).

${ }_{63}$ «¿Es que para estas personas no va a haber derechos laborales con costes económicos? ¿Es que la ley del impuesto sobre la renta de las personas físicas no se les va a aplicar con las desgravaciones consiguientes? Hay costes económicos» (Torme, DS Congreso 17 de marzo de 2005, p. 3778a); no hemos logrado algo fundamental, el informe económico; se dice que los homosexuales podrán acceder a más prestaciones, pero también que el «proyecto no supone ningún aumento de gasto y que no crea ninguna prestación, por lo que no procede estimar coste alguno [...]. ¿Qué se nos está diciendo? ¿Que estas personas no van a poder tener derecho a pensión dado que el Gobierno no lo ha previsto económicamente? ¿Que los homosexuales no van a poder heredar? [...] ¡Pues claro que hay costes económicos, señorías! Y si ésta fuera una propuesta seria [...] se habría analizado el importe económico, que les aseguro que es bastante» (Vindel, DS Senado 22 de junio de 2005, pp. 2520b-2521a). Contra: «ninguna consideración de orden ajeno a este debate de valores debe tener lugar», y menos las que afirman que «el matrimonio entre personas del mismo sexo requiere una evaluación de gasto»; es innoble «vincular una extensión de derechos» a algún perjuicio económico o a la «desestabilización de las variables de nuestro bienestar» (López Aguilar, DS Congreso 17 de marzo de 2005, p. 3773a); hablar aquí del coste «es no tener en cuenta la dignidad de la persona» (García Suárez, DS Congreso 17 de marzo de 2005, p. 3782b).

${ }_{64}$ Así, Duran i Lleida (DS Congreso 17 de marzo de 2005, p. 3775a) o Montón (DS Congreso 30 de junio de 2005, p. 5227b). También hubo alusiones a los costes de depuración del ordenamiento jurídico: «tras la aprobación del matrimonio para personas del mismo sexo en Ontario, Canadá, se ha tenido que borrar nada menos que de 73 leyes toda mención a la existencia de dos sexos» (Vindel, DS Senado 22 de junio de 2005, p. 2522a).

${ }^{65}$ Es un proyecto de enorme «potencia simbólica, social y política», que cumple «un compromiso expreso del programa electoral» (López Aguilar, DS Congreso 17 de marzo de 2005, pp. 3769a-3769b) y logrará «que la sociedad en su conjunto mejore su mentalidad cívica, colectiva y social, que buena falta nos hace» (Rodríguez Sánchez, DS Congreso 21 de abril de 2005, p. 4111a); parece «una discusión semántica inútil, pero [...] a veces las cuestiones semánticas son muy importantes» (Casas, DS Senado 14 de junio de 2005, p. 2b), y la igualdad 
que también provocará efectos positivos de alcance general. Cabe añadir aquí que los parlamentarios del partido en el gobierno aprovechan una y otra vez para recordar que están cumpliendo un compromiso electoral, lo cual persigue el efecto (simbólico) de incrementar la confianza de los ciudadanos en su tarea política. Para los detractores del proyecto, por el contrario, el proyecto no es sino un plan propagandístico en busca de titulares de prensa y una apropiación ilegítima de la bandera homosexual ${ }^{66}$.

Quizá lo más interesante de la discusión sobre el valor simbólico de esta ley sea, con todo, que revela una tensión entre dos modos de afrontar la relación de condicionamiento mutuo entre Derecho y sociedad. La posición conservadora no desea utilizar medios legales para impulsar o favorecer un determinado cambio social — por decirlo así, la sociedad habría de evolucionar a su ritmo—, sino sólo para reconocer legislativamente modelos de pareja y de familia que comienzan a proliferar y precisan, por tanto, de un marco de seguridad jurídica. El legislador debería «reaccionar» ante la nueva realidad social, pero no prefigurarla, sobre todo cuando ello pueda afectar en algún sentido a las bases axiológicas de la comunidad: en temas de este calado, el Derecho debe limitarse a regular aquello que en la sociedad no suscita controversia. Los valedores de la reforma adoptan, por el contrario, una postura «proactiva». Aunque afirman que la ley se limita a «elevar a legal lo que es real», la verdad es que la reforma va mucho más allá ${ }^{67}$ : refleja, es cierto, convicciones y preferencias de una parte significativa de la sociedad, pero aspira también a cambiar la mentalidad de otra parte y, sobre todo, a suprimir a medio plazo el disvalor que en la moral positiva todavía está asociado a la homosexualidad.

\subsection{Relaciones con otros planos de justificación}

Con fines analíticos, la discusión legislativa puede segmentarse por niveles; en nuestro caso, interesaba la eficacia (R3) y la efectividad (R4), como también hubiera sido posible adoptar un enfoque jurídico-constitucional (R2) o ético-moral (R5). Pero lo más

\footnotetext{
pasa por las «categorías terminológicas» (Etxegoyen, DS Senado 22 de junio de 2005, p. 2516b); la ley es «un potente instrumento de integración» (Rodríguez Rodríguez, DS Congreso 30 de junio de 2005, p. 5220b); vid. López Aguilar (DS Congreso 17 de marzo de 2005, p. 3769b), Ayala (DS Senado 22 de junio de 2005, p. 2513a) y Rodríguez Zapatero (DS Congreso 30 de junio de 2005, p. 5228b).

${ }_{66}$ «Vienen pregonando de manera propagandística esta medida diciendo que es la única forma posible de eliminar la discriminación»; «atribuirse la representación de los derechos e intereses de los homosexuales [...] no les corresponde», y «además es una gran tontería», pues «nos preocupan a todos» (Torme, 17 de marzo de 2005, pp. 3776b y 3778a); «esa proclamación de cómo el valor de un partido se mide por el grado de cumplimiento de su programa electoral va a ser sin duda muy repetida»; «lástima que el Partido Socialista no [...] ponga el mismo empeño en cumplir el resto de su programa» (Conde, DS Senado 14 de junio de 2005, p. 11a-b); «personas que nos acompañan en la tribuna, afiliados del Partido Popular que en su condición de homosexuales han luchado activamente en contra de la discriminación [...], que demandaban una regulación que acabara con la inseguridad jurídica [...] en las parejas formadas por personas del mismo sexo. Pues bien, estas personas que forman parte de nuestro partido se sienten cómodas, se sienten representadas en él y sus reivindicaciones se plasmaron en nuestro programa electoral y en la ponencia [...] que se aprobó en el último congreso nacional. [...] Atribuirse en exclusiva [...] la representación de los intereses y de los derechos de los homosexuales no tiene ningún sentido» (Torme, DS Congreso 21 de abril de 2005, p. 4117b).

${ }^{67}$ A veces «el derecho va en elefante y la realidad social en Fórmula 1» (Díaz Tejera, DS Senado 14 de junio de 2005, p. 5b), y «el legislador va a remolque de los cambios sociales» (Bofill, DS Senado 22 de junio de 2005 , p. 2517b); esta ley consigue «que el derecho no llegue tarde ni vaya a remolque» (Navarro, DS Congreso 30 de junio de 2005, p. 5221a).
} 
normal, en la práctica, es que las líneas argumentativas operen en varios niveles a la vez, de modo que, por ejemplo, una confrontación dentro de uno de ellos se intente resolver apelando a otro - ahí radica un aspecto de la idea de razonabilidad (R6)_. Esa imbricación aparecía ya al reconstruir los distintos argumentos, así que procuraré ahora recapitular cómo se reflejan en la discusión sobre eficacia y efectividad las relaciones entre planos de justificación ${ }^{68}$.

R3-R4. Entre los dos niveles estudiados aquí, la eficacia o racionalidad pragmática (R3) y la efectividad o racionalidad teleológica (R4), aparecen dos vínculos, si bien sólo en la argumentación contraria al proyecto. Como hemos visto, la oposición aduce el rechazo e inaplicación de la ley por parte de jueces y funcionarios para cuestionar que la norma logre cumplir sus fines; $y$ asimismo anuda el escaso número de destinatarios con la inexistencia de una demanda social, lo que le sirve a su vez para criticar la necesidad de la ley. Este planteamiento es expresión de una relación de continuidad entre los dos niveles: una menor racionalidad pragmática comportaría una menor racionalidad teleológica.

R4/R3-R5. Entre los planos de la efectividad (R4) y de la justificación ético-moral (R5) pueden identificarse dos conexiones argumentativas. La más evidente se encuentra en la discusión consecuencialista que ocupa buena parte de los debates: las conclusiones de la argumentación empírica sobre los efectos de la adopción son premisas fácticas en el juicio acerca de la corrección moral de la ley. La segunda conexión se refiere a la eficiencia del medio elegido. Aunque el coste de una ley suele discutirse al margen de su justificación moral, en los debates analizados aparecen como razones contrapuestas o en conflicto. La oposición alega que el proyecto implica un gran coste económico y que el gobierno no se ha molestado en estimarlo, y en ese sentido plantea un argumento de eficiencia (R4); el gobierno no sólo no discute los costes, sino que niega incluso que la dimensión económica sea relevante aquí, ya que la justificación de la ley responde a razones morales (R5): por lo menos cuando se trata de erradicar esta discriminación, el coste económico del proyecto no importaría. También la movilización (R3) y el valor ético-moral (R5) están conectados en la argumentación de los parlamentarios. Como en el caso anterior, que una norma sea utilizada en la práctica, o no, es independiente de su corrección, pero, frente al argumento de eficacia pragmática que aduce la oposición — la movilización de la norma será escasa-, el gobierno opone de nuevo razones de justicia; a diferencia de los costes, con todo, sí entra a valorar el número de potenciales destinatarios.

R3/R4-R2. La ley afecta a cualesquiera disposiciones que se refieran al matrimonio y se proyecta sobre todo el ordenamiento jurídico, pero dado que consiste básicamente en la adición de un párrafo al código civil, su sistematicidad apenas se discute. En cambio, otros aspectos vinculados a la racionalidad jurídico-formal juegan un papel destacado. Veíamos antes que una de las tensiones habituales al legislar surge entre la racionalidad teleológica (R4) y la jurídica (R2). En nuestro caso se aprecia al menos

${ }_{68}$ Pese a que el objeto de la discordia es el uso de la palabra «matrimonio», en los debates no se abordaron problemas de racionalidad lingüística (R1) en relación con la formulación del párrafo añadido al art. 44 del Código Civil, por lo que no consideraré aquí este plano de justificación. Durante la tramitación legislativa sí aparecieron problemas de este tipo a propósito de la redacción de algunas frases de la exposición de motivos y de las disposiciones adicionales. 
una variante de esa tensión: el conflicto — que vertebra el conjunto del debate- entre los conceptos jurídicos de matrimonio y adopción (tal como los interpretan los grupos contrarios al proyecto) y el medio escogido para lograr los fines políticos de igualdad y no discriminación (según es presentado por el gobierno). La oposición cree que dichos conceptos serán irreconocibles e inservibles si la ley llega a aprobarse, lo cual supondría aumentar la inseguridad jurídica en este campo ${ }^{69}$; pero el tecnicismo jurídico de unos es percibido por los otros como un obstáculo al avance de la sociedad ${ }^{70}$. Acaso se eche en falta otra variante, habitual en el parlamento español, que surge a propósito de las competencias de las comunidades autónomas. Algunas de ellas habían legislado sobre las parejas o uniones de hecho, pero en el debate no se plantea que la integración de la norma estatal con las leyes autonómicas (R2) pueda ser relevante de cara a la efectividad, ni que pueda ocasionar efectos negativos o dificultar el logro de los objetivos perseguidos (R4): quienes aportan argumentos sobre competencias autonómicas de Derecho civil se mantienen en un plano estrictamente jurídico ${ }^{71}$. Por último, cabe señalar la conexión entre los argumentos de naturaleza jurídico-constitucional (R2) y los relativos a la eficacia de aplicación (R3), que surge cuando se aborda el tema de la objeción de conciencia: frente a los problemas de inaplicación basados en motivos de conciencia que prevé la oposición, el gobierno no sólo cuestiona que dichos problemas vayan a producirse de hecho, sino que desarrolla una línea argumentativa completa para demostrar que la objeción de conciencia no es aplicable y que introducir una causa de abstención específica resultaría incompatible con el objetivo de la norma (R4), provocaría inseguridad jurídica (R2) y significaría dejar el cumplimiento y la aplicación de las leyes $(\mathrm{R} 3)$ a la discreción de jueces y funcionarios ${ }^{72}$.

Como vemos, la confrontación partidista incide en el análisis conjunto de los niveles de racionalidad: las relaciones que señalaba antes en abstracto (continuidad, independencia y conflicto) ${ }^{73}$ no se pueden trasladar al debate directamente, sino que hay que considerarlas dentro del marco de la posición que sostiene cada parlamentario. Tomemos por ejemplo la relación entre R4 y R5: un diputado puede argumentar que el

69 «No es una opción respaldada por un amplio consenso político y social, [...] lo que sería garantía de la necesaria estabilidad y seguridad jurídica en cuestiones tan trascendentes» (Torme, DS Congreso 17 de marzo de 2005, p. 3777b); «llamar compraventa a la donación o a la permuta no les añade nada, absolutamente nada, pero hace inservible el concepto de compraventa, aparte de introducir serias dosis de incertidumbre e inseguridad jurídica» (Vindel, DS Senado 22 de junio de 2005, p. 2521b); para cambiar el concepto de matrimonio «lo que hay que cambiar es la Constitución, porque la ley no puede [...] cambiar el contenido de los conceptos mediante» su alteración radical (Vindel, DS Senado 22 de junio de 2005, p. 2506b).

${ }^{70}$ Ustedes «se ocultan detrás de falsos tecnicismos jurídicos» que «poco tienen que ver con el Derecho y mucho con la concepción de la sociedad» (Montón, DS Congreso 21 de abril de 2005, p. 4120a). Como vimos antes, el gobierno también cuestiona el concepto de matrimonio de la oposición con razones jurídico- constitucionales.

${ }_{71}$ Véase, por ejemplo, las intervenciones de Uría (DS Congreso 21 de abril de 2005, p. 4113 b y 30 de junio de 2005, p. 5223a) o Granado (DS Senado 14 de junio de 2005, p. 12b).

${ }^{72}$ «El funcionariado no debería poder objetar el cumplimiento de esta ley»; eso serían «subterfugios legales para no aplicar una ley [...] escrupulosamente democrática» (Bonás, DS Congreso 30 de junio de 2005 , p. 5224b); «dejar en manos de algunas autoridades el cumplimiento de la ley» va en contra de la constitución (Granados, DS Senado 14 de junio de 2005, p. 13b), abriría «una espita para que se puedan prestar alegaciones de esta naturaleza» en otras situaciones, y generaría «profunda inseguridad jurídica» (Díaz Tejera, DS Senado 14 de junio de 2005, p. 15b); vid. también la intervención de Granados (DS Senado 14 de junio de 2005, p. 13b), así como las citadas en la nota 36.

73 Véase, más arriba, el apartado 2.3, así como la nota 24. 
coste es irrelevante porque la ley obedece a razones morales (relación de independencia), y otro que la justicia no debe implicar un coste demasiado elevado (relación de conflicto). Cuál sea la relación entre los niveles de racionalidad es, pues, una cuestión de perspectiva. Y aunque para abreviar he utilizado una distinción simple entre dos posiciones (partidarios y detractores, gobierno y oposición), la estructura argumentativa resulta más compleja si atendemos a la pluralidad del arco parlamentario. Contribuye a complicar el análisis que muchas posiciones se armen con argumentos pertenecientes a niveles distintos, y que la confrontación planteada en uno tienda a extenderse a los restantes. Pero justamente al segmentar el debate por planos de justificación puede apreciarse alguna inconsistencia: por ejemplo, hacer ver que el círculo de usuarios es muy reducido (R3) respalda la tesis de que la ley es innecesaria (R4), pero contradice el gran impacto que se le asigna después como factor de desintegración social o de distorsión de las listas de espera para la adopción (R4). Aunque varios parlamentarios distinguen expresamente entre planos de justificación ${ }^{74}$, éstos suelen aparecer mezclados en las líneas argumentativas. Un caso claro es la discusión sobre efectividad, que integra argumentos empíricos y normativos sobre las consecuencias sociales del proyecto, pero también argumentos sobre sus implicaciones jurídicas. E incluso dos niveles teóricamente diferenciables pueden acabar confundidos en la argumentación: esto es lo que ocurre con la racionalidad ética (R5) y la jurídica (R2) si ésta se considera desde un enfoque sustantivo o «constitucionalista». En otras palabras: la juridificación de principios materiales permite a los parlamentarios presentar el mismo argumento apoyándose en una idea de justicia o en un precepto de la constitución, o referirse indistintamente a ciertos valores como morales o constitucionales. En nuestro caso, no obstante, es mayor la recurrencia de argumentos basados en la constitución y la jurisprudencia constitucional. A lo largo de los debates se observa cómo las razones constitucionales penetran todos los planos de justificación y se proyectan, más allá de la interpretación del art. $32 \mathrm{CE}$, sobre la mayoría de los temas puntuales discutidos. Desde este punto de vista, la constitucionalidad viene a jugar el papel de la razonabilidad legislativa «eficiencia» (R6), en el modelo de ATIENZA ${ }^{75}$.

\section{CONCLUSIONES}

El propósito de este trabajo era plantear la relación entre justificación racional y eficacia de la legislación en el marco de la argumentación parlamentaria. Después de apuntar el papel de la eficacia dentro de la racionalidad legislativa y la relevancia de la dimensión simbólica de cara a la capacidad regulativa de las leyes, he sugerido un esquema de análisis de la argumentación sobre eficacia y he tratado de aplicarlo tentati-

${ }^{74}$ López Aguilar (DS Congreso 17 de marzo de 2005, pp. 3771-3772) y Etxegoyen (DS Senado, 22 de junio de 2005, pp. 2514b-2517a).

${ }^{75} \mathrm{La}$ combinación óptima entre las distintas dimensiones de racionalidad no se tematiza explícitamente, pero sí encontramos varias alusiones a la ponderación entre los intereses y los bienes jurídicos en liza, o a la proporcionalidad de la medida legislativa: esta ley «no mantiene el equilibrio necesario entre la ampliación de derechos civiles para la minoría homosexual y la salvaguarda de intereses generales» (Vindel, DS Senado 14 de junio de 2005, p. 9a, citando a una senadora de Entesa Catalana); y existen dudas de que «sea proporcionada en sentido estricto, a partir de una ponderación de los bienes, valores e intereses en juego» (Casas, DS Senado 22 de junio de 2005, p. 2502a). 
vamente a los debates sobre la ley de matrimonio homosexual. Tras este recorrido es posible extraer conclusiones en dos órdenes.

En el plano teórico interes a subrayar, primero, que los problemas de eficacia de las leyes (en sus diversas acepciones) han pasado de ser un aspecto secundario a convertirse en una de las claves de la legislación racional; esto ha de reflejarse a su vez en las deliberaciones de los parlamentarios y, por consiguiente, en una teoría de la argumentación legislativa. En el contexto de la sociedad compleja, la eficacia aparece vinculada a modelos colaborativos de legislación y a la participación social en los procesos de regulación; luego cabría decir que existe alguna correlación entre la eficacia y el carácter inclusivo o abierto - y la calidad argumentativa - de dichos procesos. En este sentido, la crisis del instrumentalismo jurídico suscita un cambio en el modo de entender la legislación simbólica: si tradicionalmente era estudiada en términos de sus funciones ideológicas, ahora revela su potencial regulativo al conectarse con prácticas discursivas desarrolladas en la sociedad a partir de los principios y topoi expresados en la ley.

En segundo lugar, el examen del debate legislativo sobre el matrimonio entre personas del mismo sexo indica algunas tendencias que sería bueno contrastar en análisis ulteriores ${ }^{76}$. Hemos visto, así, que la argumentación sobre cuestiones de eficacia está presente en leyes que no imponen obligaciones o prohibiciones ni precisan de implementación, y que puede ser central incluso en áreas que no asociamos con el derecho regulativo. En los debates analizados, el grueso de la discusión sobre eficacia alude a la efectividad o racionalidad instrumental del medio legal para la consecución del fin perseguido, y más en concreto a su impacto y efectos sociales. Hemos comprobado también que resulta difícil encontrar a ese respecto argumentos empíricos o fácticos puros, pues la interpretación de la realidad y la previsión de consecuencias sociales quedan unidas a valoraciones normativas; y que los argumentos relativos a la movilización o al número de potenciales usuarios de la ley y a su eficiencia o coste económico, por lo menos en este caso, se subordinan a las razones de naturaleza moral y constitucional. El esquema de trabajo propuesto, en fin, ha permitido reconstruir y estructurar la deliberación acerca de la eficacia y la efectividad, así como señalar sus conexiones con otros niveles de racionalidad legislativa. Y aunque resta todavía desarrollar criterios cualitativos para evaluar la corrección de los argumentos, este esquema parece mostrarse útil para abordar la complejidad de la argumentación parlamentaria como fuente de justificación y, por tanto, de legitimidad del derecho.

\section{REFERENCIAS}

AGUILÓ, J., 2006: «"Tener una constitución”, “darse una constitución” y “vivir en constitución”», Conferencia de clausura del II Congreso Brasileiro de Filosofia e Teoria geral do Direito, Recife.

${ }^{76}$ En el caso estudiado es prioritaria la discusión moral y constitucional: la eficacia —no así la efectividad - se tematiza por vía de alusiones breves e indirectas que han tenido que ser reconstruidas. Analizar otros tipos de normas, en las que sean cruciales temas como el cumplimiento (leyes penales o fiscales) o la implementación (por ejemplo, la llamada ley de dependencia), permitiría establecer comparaciones entre diferentes áreas de regulación en cuanto al tratamiento argumentativo de los problemas de eficacia. 
AleXy, R., 2008: «The Reasonableness of Law and Legal Argumentation», Seminario Visiones del Derecho, Alicante.

AmunÁtegui, C. DE, 2005: «Argumentos a favor de la posible constitucionalidad del matrimonio entre personas del mismo sexo», Revista general de legislación y jurisprudencia, 3, pp. 351368.

AtIENZA, M., 1987: «Para una razonable definición de "razonable”», DOXA, 4, pp. 189-200.

- 1997: Contribución a una teoría de la legislación, Madrid: Civitas.

- 2005: «Reasoning and Legislation», en L. WinTGENS (ed.)., The Theory and Practice of Legislation, Aldershot: Ashgate, pp. 297-317.

Ayres, I., y BRAITHWAITE, J., 1992: Responsive Regulation, Oxford: Oxford UP.

BALDwIN, R., 1997: «Regulation: After Command and Control», en K. HawKInS (ed.), The Human Face of Law: Essays in Honour of Donald Harris, Oxford: Oxford UP.

BALDwIN, R., y Black, J., 2008: «Really Responsive Regulation», The Modern Law Review 71/1, pp. 59-94.

Bizer, M. et al., (eds.), 2002: Responsive Regulierung, Tübingen: Mohr Siebeck.

BLACK, J., 1998: «Regulation as Facilitation», The Modern Law Review, 61/5, pp. 621-660.

BLANKENBURG, E., 1977: «Über die Unwirksamkeit von Gesetzen», ARSP, LXIII/1, pp. 31-57.

- 1986: «Rechtssoziologie und Rechtswirklichkeitsforschung», en W. SCHRECKENBERGER (ed.), Gesetzgebungslebre: Grundlagen, Zugänge, Anwendung, Stuttgart: Kohlhammer, pp. 109120.

BlÁzQuez, B., y MoRATA, B., 2005: «La implementación de las políticas públicas: modelos analíticos y el papel de la administración pública», en M. PÉrEZ SÁNCHEZ (ed.), Análisis de Políticas Públicas, Granada: EUG.

BöHret, C., y Konzendorf, G., 2001: Handbuch Gesetzesfolgenabschätzung, Baden-Baden: Nomos.

BROCKER, L., 2002: «Parlamentarische Gesetzesfolgenabschätzung», en M. BizER et al., (eds.), Responsive Regulierung, Tübingen: Mohr Siebeck, pp. 133-141.

Calvo, M., 2005: Transformaciones del Estado y del Derecho, Bogotá: Universidad Externado.

Calsamiglia, A., 1989: «Justicia, eficiencia y optimización de la legislación», Documentación Administrativa, 218/219, pp. 111-151.

— 1993: «¿Debe ser la moral el único criterio para legislar?», DOXA, 13, pp. 161-178.

CAPELla, J. R., 1997: Fruta prohibida, Madrid: Trotta.

CERDEIRA, G., 2005: «¿Es constitucional, hoy, el matrimonio "homosexual" (entre personas de idéntico sexo)?», Revista de Derecho Privado, 89, pp. 37-56.

COTTERRELL, R., 1993: Introducción a la sociología del derecho, Barcelona: Ariel.

COUNCIL OF EUROPE, 2001: Evaluation of Legislation, Strasbourg: Council of Europe.

DE BAKKER, E., 2003: «Der (beinahe) weisse Fleck der Legitimitätsforschung», Zeitschrift für Rechtssoziologie, 24, pp. 219-247.

DelGado, J., 2006: «Notas sobre la eficacia social de distintos tipos de normas civiles», DOXA, 29, pp. 195-218.

DíEZ-PiCAZO, L. M., 2007: «En torno al matrimonio entre personas del mismo sexo», InDret-Revista para el Análisis del Derecho, 2, pp. 1-12.

DíEz Ripollés, J. L., 2002: «El derecho penal simbólico y los efectos de la pena», Boletín Mexicano de Derecho Comparado, 103, pp. 63-97.

- 2003: La racionalidad de las leyes penales, Madrid: Trotta.

DomíngueZ, P., 2006: «Las uniones de personas del mismo sexo: las opciones de regulación y sus implicaciones jurídicas», Derecho Privado y Constitución, 20, pp. 173-202. 
Eskridge, W., y Ferejohn, J., 2001: «Super-Statutes», Duke Law Journal, 50, pp. 1215-1276. Feteris, E. T., 2002: «A Pragma-Dialectical Approach of the Analysis and Evaluation of Pragmatic Argumentation in a Legal Context», Argumentation, 16/3, pp. 349-267.

FigeroA, A., 1995: «La evaluación del Derecho», en A. FigueroA (coord.), Los procesos de implementación en las normas jurídicas, Vitoria-Gasteiz: IVAP, pp. 11-28.

Friedman, L. M., 1975: The Legal System, New York: Russell Sage Foundation.

FÜHR, M., 2002: «Der Grundsatz der Verhältnismaßigkeit als metodischer Brückenschlag», en M. BizER et al. (eds.), Responsive Regulierung, Tübingen: Mohr Siebeck, pp. 91-113.

GAVIDIA, J. (coord.), 2007: La reforma del matrimonio: Leyes 13 y 15/2005, Madrid: Marcial Pons. GRIFFITHS, J., 2003: «The Social Working of Legal Rules», Journal of Legal Pluralism, 48, pp. 184.

- 2005: «An Introduction in Eight Propositions to the Social Working Approach to Legislation», en N. ZEEGERS et al. (eds.), Social and Symbolic Effects of Legislation under the Rule of Law, New York: E. Mellen, pp. 7-18.

HABERMAS, J., 1998: Facticidad y validez, Madrid: Trotta.

HierRo, L., 2003: La eficacia de las normas jurídicas, Barcelona: Ariel.

- 2003: Justicia, igualdad y eficiencia, Madrid: CEPC.

INGRAM, H., 1990: «Implementation: A Review and Suggested Framework», en N. B. LyNn y A. Wildavsky (eds.), Public Administration. The State of the Discipline, Chatham: Chatham House.

Johnson, R. H., 2000: Manifest Rationality: A Pragmatic Theory of Argument, Mahwah: Erlbaum.

Karpen, U. (ed.), 2002: Evaluation of Legislation, Baden-Baden: Nomos.

Kindermann, H., 1988: «Symbolische Gesetzgebung», en D. Grimm y W. MAiHOFER (eds.), Gesetzgebungstheorie und Rechtspolitik, Opladen: Westdt, Verlag, pp. 222-245.

— 1989: «Alibigesetzgebung als symbolische Gesetzgebung», en R. VOIGT (ed.), Symbole der Politik, Politik der Symbole, Opladen: Westdt, Verlag, pp. 257-273.

KIßLER, L., 1984: Rechtssoziologie für die Rechtspraxis, Neuwied: Luchterland.

KÖCK, W., 2002: «Gesetzefolgenabschätzung und Gesetzgebungsrechtslehre», Verwaltungs-Archiv, 93/1, pp. 1-21.

KÖNIG, K., 1989: «Sobre la evaluación de los programas estatales», Documentación Administrativa, 218/219, pp. 413-428.

LA SPINA, A., 1989: La decisione legislativa. Lineamenti di una teoria, Milano: Giuffrè Editore.

LIPARI, N., 1990: «La formación negocial del derecho», Anales de la Cátedra F. Suárez, 30, pp. 13 26.

MADER, L., 2002: «The Evaluation of Draft Laws», en U. KARPEN (ed.), Evaluation of Legislation, Baden-Baden: Nomos, pp. 102-115.

Maestro, G., 1991: «Negociación y participación en el proceso legislativo», Revista de Derecho Político, 32, pp. 55-118.

MarCILLA, G., 2005: Racionalidad legislativa, Madrid: CEPC.

Montoro, M. J., 2001: La evaluación de las normas, racionalidad y eficiencia, Barcelona: Atelier.

NAvarro, P. E., 1990: La eficacia del derecho, Madrid: CEC.

Nonet, Ph., y SElznick, Ph., 1978: Law and Society in Transition, New York: Octagon.

OsÉs, J., 1994: «El control del cumplimiento de las normas», en J. M. CORONA et al. (coords.), La técnica legislativa a debate, Madrid: Tecnos, pp. 279-293.

Pérez Sánchez, M. (ed.), 2005: Análisis de Politicas Públicas, Granada: EUG.

Prieto Sanchís, L., 2005: Apuntes de Teoría del Derecho, Madrid: Trotta. 
RADAELLI, C. M. (ed.), 2001: L'analisi di impatto della regolazione in prospettiva comparata, Soveria Mannelli: Rubbetinno.

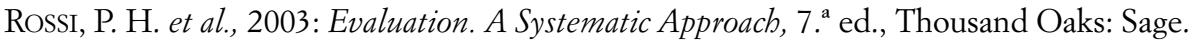

SAMPFORD, Ch., 1989: The Disorder of Law. A Critique of Legal Theory, Oxford: Blackwell.

Sieckmann, J. R., 2005: «Argumentation im Parlament», en J. R. SiEckmann (ed.), Verfassung und Argumentation, Baden-Baden: Nomos, pp. 115-128.

SteEnBergen, M. R. et al., 2003: «Measuring Political Deliberation: A Discourse Quality Index», Comparative European Politics, 1, pp. 21-48.

STEINER, J. et al., 2004: Deliberative Politics in Action, Cambridge: Cambridge UP.

Teubner, G., 1983: «Substantive and Reflexive Elements in Modern Law», Law and Society Review, $17 / 2$, pp. $239-285$.

— 1986: «After Legal Instrumentalism? Strategic Models of Post-Regulatory Law», en G. TEUBNER (ed.), Dilemmas of Law in the Welfare State, Berlin: W. de Gruyter, pp. 229-325.

TuORI, K., 2002: Critical Legal Positivism, Aldershot: Ashgate.

VALIERES, A., 2007: «La prohibición del matrimonio entre cónyuges del mismo sexo como discriminación por razón de orientación sexual», Revista de Derecho Político, 68, pp. 295-314.

VAn AECKen, K., 2005: «Legal Instrumentalism Revisited», en L. Wintgens (ed.)., The Theory and Practice of Legislation, Aldershot: Ashgate, pp. 67-92.

VAn Der BurG, W., 2005: «The Irony of a Symbolic Crusade: The Debate on Opening Up Civil Marriage to Same-Sex Couples», en N. ZEEgERS et al. (eds.), Social and Symbolic Effects of Legislation under the Rule of Law, New York: Edwin Mellen, pp. 245-276.

Van Eemeren, F. H., y Grootendorst, R., 2003: «A Pragma-dialectical Procedure for a Critical Discussion», Argumentation, 17/4, pp. 365-386.

VAn HoEcKe, M., 2002: Law as Communication, Oxford/Portland: Hart.

Weber, M., 1969: Economía y sociedad, México DF: FCE.

WitteveEn, W. J., 1994: «Legislation and the Fixation of Belief», en R. KeveLson (ed.), The Eyes of Justice. Seventh Round Table on Law and Semiotics, New York: Peter Lang, pp. 319343.

— 1999: «Significant, Symbolic and Symphonic Laws», en H. van SCHOOTEN (ed.), Semiotics and Legislation, Liverpool: Deborah Charles, pp. 27-70.

- 2005: «Turning to Communication in the Study of Legislation», en N. ZeEGERS et al. (eds.), Social and Symbolic Effects of Legislation under the Rule of Law, New York: E. Mellen, pp. 1744.

Witteveen, W. J., y van KLINK, B., 1999: «Why Is Soft Law Really Law? A Communicative Approach to Legislation», RegelMaat, 14/3, pp. 126-140.

WRÓBLEWSKI, J., 1990: «Principles, Values and Rules in Legal Decision-Making and the Dimensions of Legal Rationality», Ratio Iuris, 3/1, pp. 100-117. 